\title{
DOS SIGLOS DE CARTOGRAFÍA EN LA FRONTERA DEL ALTO RIO NEGRO - VAUPÉS ENTRE COLOMBIA Y BRASIL 1774-1976
}

\author{
Gabriel Cabrera $^{1}$
}

\begin{abstract}
RESUMEN
Este artículo explora la cartografía existente desde 1774 hasta 1976 sobre la región fronteriza del Alto Río Negro - Vaupés entre Colombia y Brasil. Ocupada tradicionalmente los pueblos indígenas de filiación Tucano oriental, Arawak y Makú. El texto ofrece un panorama de las fuentes existentes sobre el tema en los dos países, traza un panorama de los primeros mapas sobre la Amazonia y de la región del estudio, ilustrando con una zona concreta la evolución cartográfica sobre la zona.
\end{abstract}

Palabras-clave: Amazonia. Mapas. Cartografia. Alto Rio Negro - Vaupés.

\section{RESUMO}

Este artigo explora a evolução da cartografia no Alto Rio Negro -Uaupés na fronteira da Colômbia e Brasil entre 1774 e 1976. Com uma população predominantemente indígena das famílias Tukano oriental, Arawak y Makú. O texto oferece uma relação das fontes cartográficas, os primeiros mapas acerca da Amazônia e descreve os mapas da região do estudo e suas mudanças com um exemplo concreto.

Palavras-chave: Amazônia. Mapas. Cartografia. Alto Rio Negro - Uaupés.

Submetido em: 07.03 .2020

Aprovado em: 16.03 .2020

\section{INTRODUCCIÓN}

En 1901 el conocimiento sobre la región amazónica estaba circunscrito al cauce de los principales ríos y el resto de la región se nombra como inexplorada (Mapa 1). Aunque contamos con estudios sobre otras fuentes visuales para la región como la acuarela (CABRERA, 2015) y la fotografía (CABRERA, 2018a; CABRERA, 2018b) son escasos los de mapas. Como recuerda un investigador "los mapas son perspectivas del mundo en el momento en que fueron hechos" (HARLEY, 2005, p. 140) y bajo esta premisa, el propósito de este texto es ocuparse de la evolución cartográfica en la zona de frontera de Brasil y Colombia del Alto Río Negro - Vaupés. Para el efecto esta presentación cubre tres tópicos, las fuentes para el estudio cartográfico de la amazonia, los primeros mapas, y una mirada concreta sobre una región de la zona propuesta.

\footnotetext{
1 Profesor Asociado del Departamento de Historia. Universidad Nacional de Colombia - Sede Medellín. gcabrerabe@unal.edu.co
} 


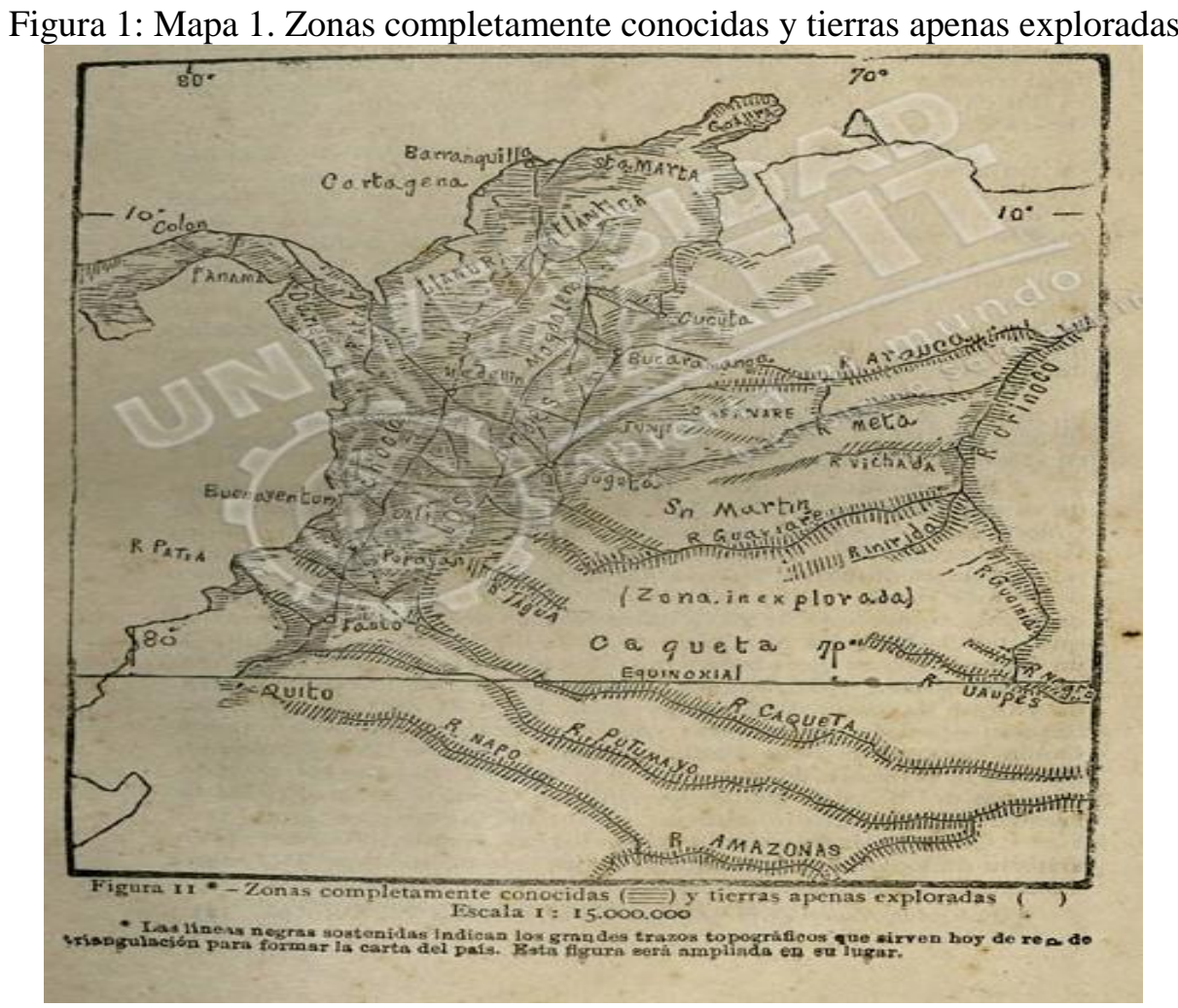

Fuente: Vergara y Velasco, 1901

\section{FUENTES PARA ESTUDIAR LOS MAPAS EN LA FRONTERA}

Una aproximación a la cartografía histórica portuguesa puede hacerse a través de: $L a$ cartografia da região amazônica: catálogo descritivo (1500-1961) que contiene una relación de 42 mapas sobre la Amazonia (ADONIAS, 1963, p. 117-155); y Os mapas do descobrimento (Ministério das Relações Exteriores de Brasil 2000); así como del catálogo conmemorativo de los 500 años del Brasil que incluyen una síntesis de esta cartografía antigua (GUEDES, 2000, p. 96-101). Otro material impreso es la Cartografía histórica portuguesa. Catálogo de Manuscritos siglos XVII-XVIII (MANSO, 1999).

Otros fondos con mapas de Brasil son el Arquivo Público de Pará que contiene 616 mapas $^{2}$ y el Centro cultural dos Povos da Amazônia que ofrece algunos mapas digitalizados y un número desconocido de mapas. El IHGB tiene un total de 2.213 mapas, 63 de los cuales están digitalizados (COSTA, 2013, p. 640). Igualmente, en Brasil la Fundação Biblioteca Nacional y en Portugal la Biblioteca Nacional, El Arquivo Nacional Ultramarino que ya tiene su catálogo (FARIA, 2011) y el Arquivo da Torre do Tombo tienen sus secciones cartográficas y algunos mapas ya están digitalizados (VARGAS; GARCÍA, 2007, p. 3).

\footnotetext{
${ }^{2}$ http://www.fcptn.pa.gov.br
} 
Hasta el siglo XX la cartografía brasileña es numerosa, siendo la Carta Geográfica do Brasil de 1922 que siguió en su elaboración los lineamientos internacionales de la convención de París de 1913, impresa en Berlín, el mapa que se considera la primera carta científica del Brasil, Penha (1993 apud SANTOS; CASTIGLIONE, 2014, p. 3).

El desarrollo cartográfico en Brasil debe al IBGE, pues desde 1938 recogió las iniciativas del Conselho Brasileiro de Geografia. Dentro de sus primeras tareas adelantó la Campanha dos Mapas Municipais que ordenaba que todas las alcaldías elaborar sus mapas municipales en un período de dos años y en caso de no hacerlo sus territorios serían anexados a municipios vecinos que hubiesen cumplido el compromiso.

Los entonces 1574 municipios cumplieron y el resultado fue presentado en la Exposição dos Mapas Municipais el 29 de mayo de 1940. Igualmente, en 1940 se editaron 100.000 ejemplares del Mapa do Brasil en escala 1:6.500.000 en conmemoración del 5 Recensamento Geral do Brasil. Este fue distribuido en todo el país en las escuelas de enseñanza básica para que fueran colgados en los salones (SANTOS; CASTIGLIONI, 2014, p. 5-6).

En los años sesenta se incorporó la aerofotografía, aunque sobre la Amazonia fue imposible trabajar con este método por la permanencia y dinámica de las nubes. Hacia 1970 apareció la Revista Brasileira de Cartografía y desde 1973 se agregaron a los satélites como fuente de información y se adelantó un convenio entre el IBGE y la SUDAM para registrar $345.000 \mathrm{~km}^{2}$ en escala 1:100.000. A comienzos de los años ochenta se incorporó la computación como instrumento de análisis de datos y en 1985 se adelantó el Projeto Radam Brasil.

Para los años noventa la automatización generó 5507 mapas municipales estadísticos por el sistema SISCART que fueron empleados durante el Censo Demográfico del año 2000 (SANTOS; CASTIGLIONI, 2014, p. 7-15). Finalmente, cabe mencionar dos esfuerzos más: la Divisão de Cartografia da Biblioteca Nacional procesa la información de la entidad y promueve los encuentros Luso-brasileros de cartografía histórica desde 1998 y recientemente la Univesidade de São Paulo creo el portal de cartografía histórica.

Sobre los dominios españoles contamos con el Catálogo Mapoteca. Sección de Mapas y Planos (AGN, 2005) y los Atlas histórico geográfico (BLANCO, 1992) y Atlas de mapas antiguos de Colombia: siglos XVI a XIX (ACEVEDO, 1997). La Biblioteca Nacional de Colombia y la Biblioteca Luis Ángel Arango tienen una cartografía digitalizada que incluye mapas de América, algunos mapas portugueses y planos que datan de los siglos XVI a XVIII. 
Naturalmente, en España hay fondos como el Archivo General de Indias "que conserva cerca de siete mil mapas, planos y dibujos sobre América. Allí, de 403 unidades referidas a Colombia, Panamá y Quito 26 corresponden al siglo XVI, 130 al siglo XVII, 199 al siglo XVIII, 47 al siglo XIX y una al siglo XX” (TOVAR, 2009a, p. 245). Para esta última unidad hay un catálogo sobre mapas de Panamá, Santafé y Quito (TORRES LANZAS, 1985). Igualmente, en el Archivo de Simancas, en el Museo Naval y en la Biblioteca Nacional de España hay acervos cartográficos (VARGAS; GARCÍA, 2007, p. 3).

La Sociedad Geográfica de Colombia constituida en 1903 publica desde 1907 el Boletín de la Sociedad Geográfica. El desarrollo cartográfico colombiano está ligado a la creación en 1902 de la Oficina de Longitudes y Fronteras adscrita al Ministerio de Relaciones Exteriores cuyas actuaciones comenzaron en 1910 y que hasta 1925 determinó la longitud con respecto a Bogotá y posición astronómica de más de 1.000 puntos del territorio nacional y otras tantas altitudes. Estos elementos fueron las bases para generar una cartografía de mapas en escala 1:500.000 pero insuficiente para mayores escalas. Esta oficina funcionó hasta 1935 cuando se creó el Instituto Geográfico con dirección militar. La entidad contaba con secciones de astronomía y geodesia, aerofotogrametría y cartografía; publicando desde 1936 publicó la Revista Geográfica de Colombia.

En 1940 el instituto asumió las tareas catastrales y desde 1950 cambio su nombre a Instituto Geográfico Agustín Codazzi. En los años setenta el interés por la Amazonia dio impulso al desarrollo del Proyecto Radargamétrico o Proradam que se ocupó del estudio de los recursos naturales y el potencial desarrollo de la región. Finalizado en 1978, se constituyó en el soporte de la publicación de una cartografía moderna del $85 \%$ de la región (MONTAÑEZ, 2000, p. 67-69). En los años noventa se incorporaron los satélites a la recolección de datos. Los resultados del Proyecto Radargamétrico y de la aplicación de sensores remotos o ORAM fueron publicados tiempo después (IGAC, 1999).

En 1822 se publicó el primer mapa impreso de la República de Colombia en Filadelfia, su existencia obedeció a las políticas de la doctrina Monroe que reconoció entonces la independencia y respaldo que cualquier incursión europea seria entendida por Estados Unidos como una amenaza; este se acompañó de notas geográficas, históricas, e informaciones comerciales y políticas (NIETO, 2010, p. 40).

Otro mapa bajo el nombre de Carta de la Republica de Colombia se publicó en 1827, este reúne las informaciones sobre Ecuador, Nueva Granada y Venezuela antes de la disolución y su elaboración estuvo bajo el mando de José Manuel Restrepo (1781-1863) quien 
fue formado en astronomía, geografía y cartografía por Francisco José de Caldas pionero del trabajo cartográfico en Colombia (NIETO, 2010, p. 43).

Pero el primer mapa oficial de Colombia como nación independiente se produjo en 1864 bajo la autoría de José María Paz, este, que coincidió con el mismo mapa para el Perú autoría de Mariano Felipe Paz Soldán, se caracterizan con relación a la zona amazónica por la "vaguedad, la falta de detalle, la imprecisión y la incongruencia entre los pocos lugares allí señalados" (ZARATE, 2018, p.19).

Tres libros recientes abordan la cartografía. Impactos Territoriales (2013) se ocupa de la transición de la colonia a la República y reúne cuatro contribuciones que permiten conocer las estructuras político-jurídicas del momento, los centros urbanos, los caminos y presencia de las instituciones, al igual que las rutas de naturalistas en el mismo período (DELGADO, 2013).

Ensamblando la nación (2010) hace un recorrido sobre el proceso de elaboración de los mapas y su evolución, enfatizando que su elaboración "no es el productos de mentes individuales ni de observaciones solitarias" sino que tras ellos está la participación de múltiples agentes dibujantes, grabadores, impresores, expedicionarios, guías locales y nativos "que conocen mejor el territorio que cualquier explorador o conquistador" (NIETO, 2010, p. 18; APPELBAUM, 2017, p. XXVIII).

Por último, Imágenes a la deriva se ocupa de la relación entre la cartografía y la idea de nación, recordando como con relación a la amazonia la perdida territorial con los países vecinos se expresa en anotaciones como la de un mapa de 1864 en la que se apuntaba con relación al trazo Tabatinga - Apaporis pactado en 1851 entre Perú y el imperio brasileño "línea que limita el territorio que pretende y ha usurpado en parte el Imperio del Brasil", es decir el Estado colombiano conocía y aceptaba la pérdida y pretensión del vecino (TOVAR, 2009b, p. 19).

Otros dos esfuerzos deben mencionarse en Colombia. El ciclo de exposiciones sobre cartografía regional adelantado por el Banco de la República que cubrió en su momento tres regiones del país publicando sus catálogos (BANCO DE LA REPÚBLICA, 2000, 1999a, 1999b) y el blog Razón cartográfica que pretende divulgar conocimientos sobre la historia de la geografía, cartografía y áreas afines. 


\section{LOS PRIMEROS MAPAS}

Existe un nutrido número de mapas generales en los que aparece el Brasil, y es un hecho cierto que fueron los ríos, la ruta de penetración y conocimiento de la región amazónica (SANTOS, 1999, p. 20). Dos mapas, el Rio de las Amazonas que descubrió Francisco de Orellana de 1544 del cartógrafo italiano Sebastián Caboto y Nueva Carta de 1597 del flamenco Jodocus Hondius son ejemplos basados en información secundaria y como en el caso del segundo se acompaña de imágenes de animales salvajes, hombres sin cabeza y las mujeres guerreras que darían origen al nombre del río (FERNÁNDEZ-SALVADOR, 2013, p. 74).

En el Archivo Histórico Ultramarino un mapa de 1637 es la primera representación del Río Amazonas que muestra su curso de Quito hasta Barra do Pará (São Luis do Maranhão), la imagen permite apreciar la posición relativa de localidades como el Cerro de Potosí, Arica, Cuzco, Cabo del Norte (DOMINGO, 2014, p. 130-133). Ver Cuadro 1.

Figura 2: Comparativo Mapas 2 y 3. Nieuwe Caerte de Jodocus Hondius de 1597 y. Río Amazonas de 1637
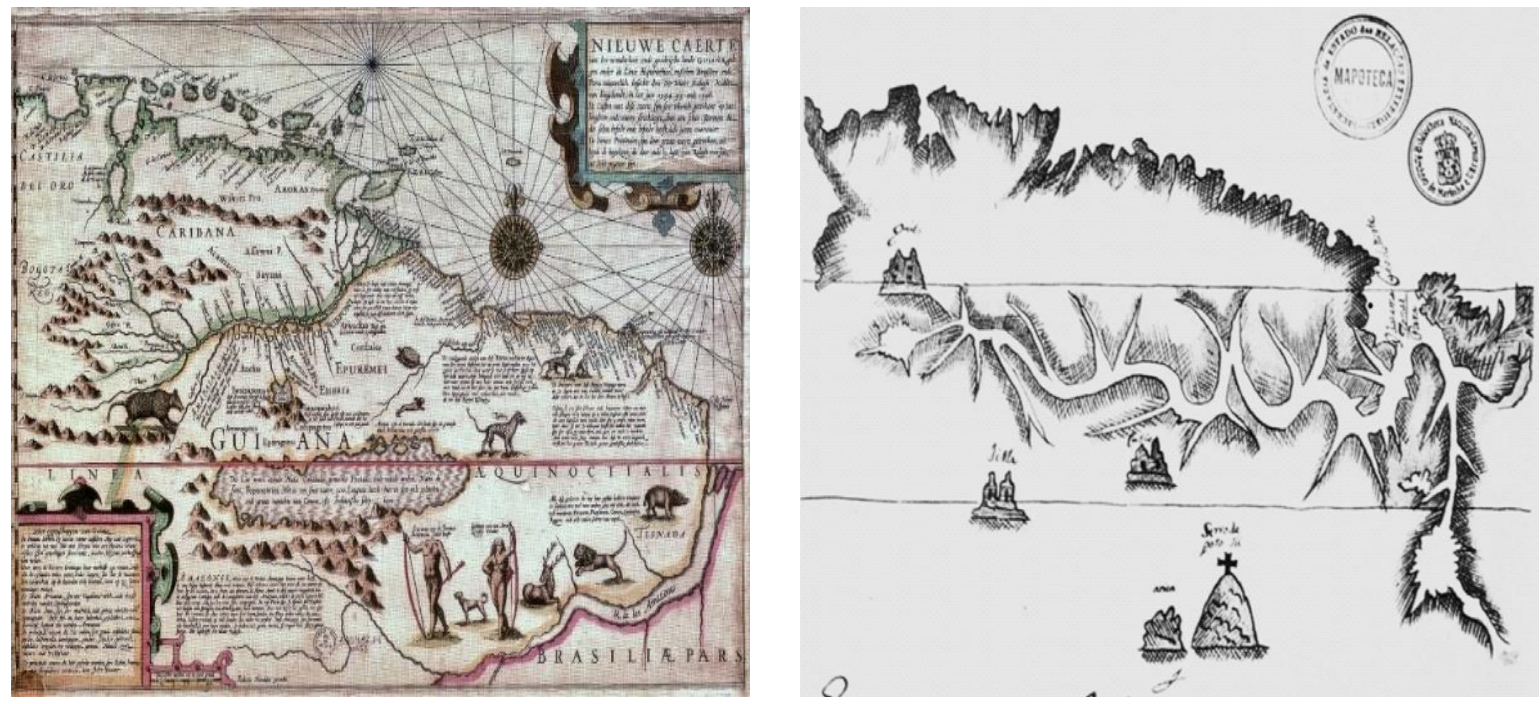

Fuentes: Fernández-Salvador, 2013; Domingo, 2014

Es el mapa de Pedro Texeira (1570-1641) la primera representación gráfica del río Amazonas; basado en su viaje hasta Quito respuesta al descenso por el rio Amazonas de los dominicos Andrés de Toledo y Domingos de Brieva que llegaron hasta Belén. Traza el curso completo del rio Amazonas desde su nacimiento a desembocadura, aunque es más un dibujo, ubica Quito, Belém, y las provincias Maguas, Solimon, Rio del Cusco, Rio Negro, Tapinambas, Trapajolos, así como el fuerte Gurupá. El trazo de línea roja indica el Ecuador, unos números revelan la relativa profundidad del Amazonas y otros muestran los grados de 
latitud que separan un lugar del otro (FERNÁNDEZ-SALVADOR, 2013, p. 76; DOMINGO, 2014, p. 134-138). En 1657 se publicó el mapa Le Perou e le course de la Riviere Amazone del francés Nicolás Sanson, basado en informaciones indirectas, se le reconoce como el primer mapa científico del río Amazonas (FERNÁNDEZ-SALVADOR, 2013, p. 82). Ver Cuadro 2.

Figura 3: Comparativo Mapas 4 y 5. Rio Amazonas de Pedro Texeira y Le Perou de Nicols Sanson.
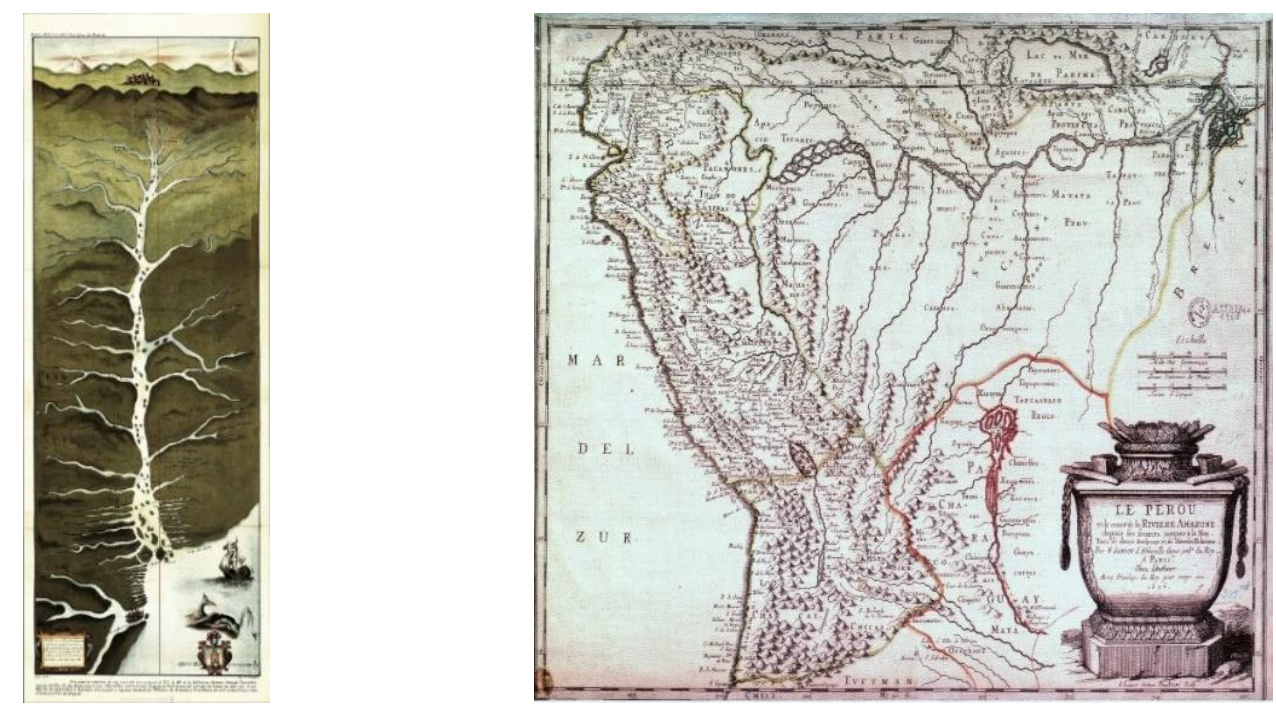

Fuente: Fernández-Salvador, 2013

El mejor mapa basado en observaciones directas es del jesuita Samuel Fritz. Dibujado con tinta en Belém en 1691, muestra todo el río Amazonas, aunque su mayor fidelidad y detalles están hacia la porción occidental de la región en donde aparecen las desembocaduras de los ríos Napo y Japurá [Caquetá] y casi todas las aldeas indígenas y misiones religiosas, como también los nombres de los principales pueblos indígenas de la región. Fue gravado en Quito en 1707 por el también jesuita Juan de Narváez bajo el título El Gran Rio Marañón o Amazonas (PORRO, 2016, p. 157).

El mapa de Fritz muestra el origen correcto del río Amazonas en la laguna de Laurinacocha y específica la distancia entre lugares utilizando como patrón de medida la legua; su versión impresa se acompaña de un listado de los misioneros jesuitas que murieron como mártires con el año y el lugar de su deceso, que se indica se incluye en el mapa con el símbolo de la cruz, elemento que reafirma la presencia y labor evangelizadora en la zona (SEVILLA y SEVILLA citadas en FERNÁNDEZ-SALVADOR, 2013, p. 83). Adicionalmente, incluye informaciones sobre plantas y animales y destaca la presencia jesuita 
que contrasta con el escaso o vacío de las informaciones en las áreas donde laboraron los franciscanos (FERNÁNDEZ-SALVADOR, 2018, p.138-139).

En 1744 Charles Maria La Condamine (1701-1774), quien con certeza conoció el mapa manuscrito de Fritz, produjo otro mapa. Matemático parisense, participó de la expedición científica de Duguay-Trouin al Mediterráneo. Fue invitado a participar de la expedición al Ecuador que estudiaría la circunferencia de la tierra y pasó nueve años en América llegando luego a ser miembro de varias academias de ciencias europeas (MEIRELLES, 2009, p. 58).

Condamine corrigió errores del mapa de Fritz como la exageración del terreno de difícil tránsito en las estribaciones de la cordillera de los Andes e incluyó el trazo del río hecho por Fritz con una línea más tenue para diferenciarlo del suyo (PORRO, 2016, p.157; SEVILLA y SEVILLA, 2013, p.91). Este mapa recibió diversas ediciones o reproducciones de cartógrafos editores como Whithers (1747), Jacques Nicoas Bellin (1773) y Maestricht (1778) (MEIRELLES, 2009, p. 61). Ver Cuadro 3.

Figura 4: Comparativo Mapas 6 y 7. El gran río Marañón de Samuel Fritz y Carte du cours do Maragnon ou de la grande riviere des Amazones de Charles Maria La Condamine
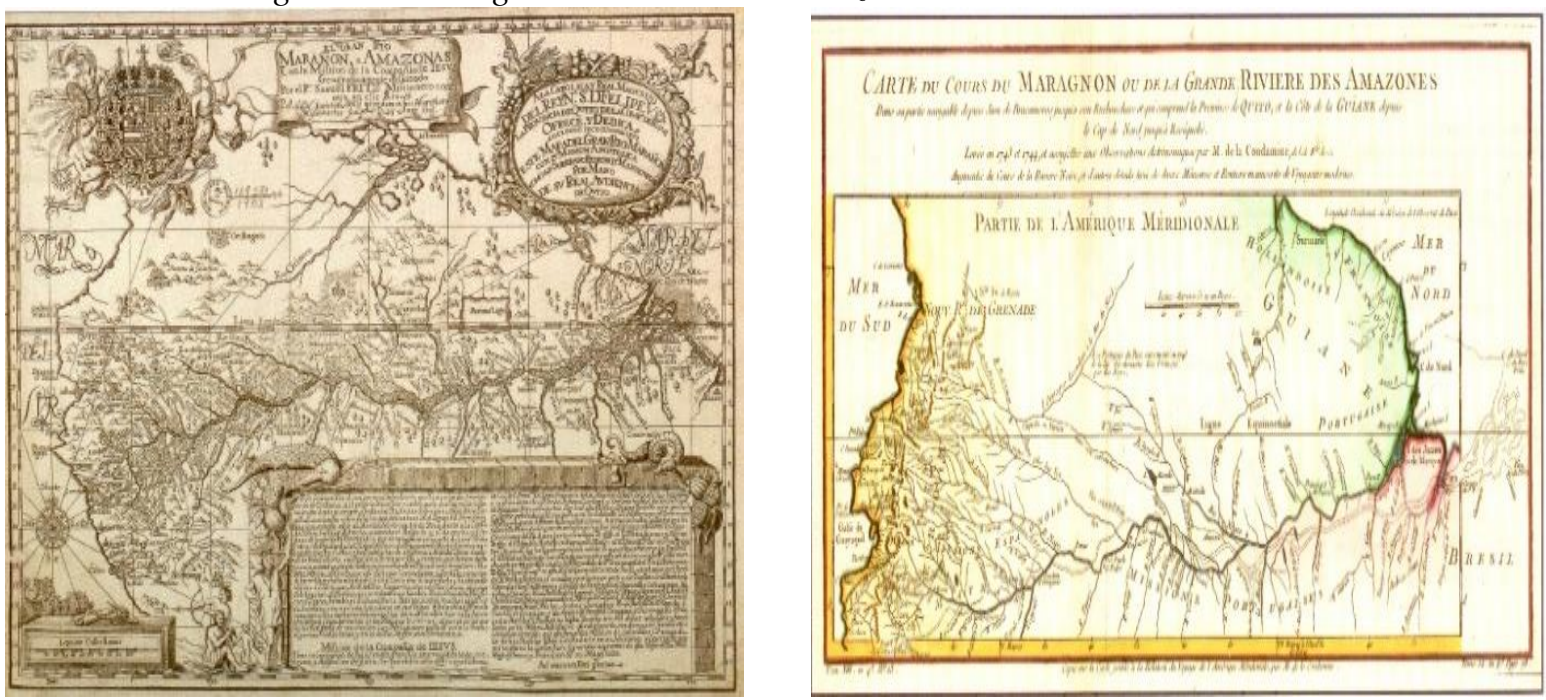

Fuente: Sevilla y Sevilla, 2013

En las Bibliotecas Nacionales de Brasil y Colombia, como en la Biblioteca Luis Ángel Arango reposan mapas generales del siglo XVIII, en ellos es clara la indicación de la zona amazónica como el país de las Amazonas y por sus fechas en algunos de ellos no aparece la comunicación Orinoco-Rio Negro a través del brazo del Casiquiare que sólo se reveló en 1744. 
El Tratado de San Ildefonso de 1777 zanjó las disputas territoriales entre las coronas española y portuguesa; pero para precisar lo acordado se organizaron cinco partidas de límites. La cuarta partida se ocupó de la amazonia. Por España el líder fue Francisco Requena y Herrera (1743-1824) cuyos detalles biográficos y de itinerario pueden seguirse en otros trabajos (BEERMAN, 1996; CABRERA, 2002, p. 88-89).

De acuerdo con Requena "Estos últimos ríos Japurá, Apaporis, Engaños, Mesay, Cuñaré nunca fueron examinados antes por algún español” (BEERMAN, 1996); confirmando como hacia el río Apaporis se dirigieron primero los portugueses. Ver Cuadro 4.

Figura 5: Comparativo Mapas 8 y 9. Carte de la Terre Ferme de Perou do Bresil et du pays des Amazonas y de Francisco Requena de 1796
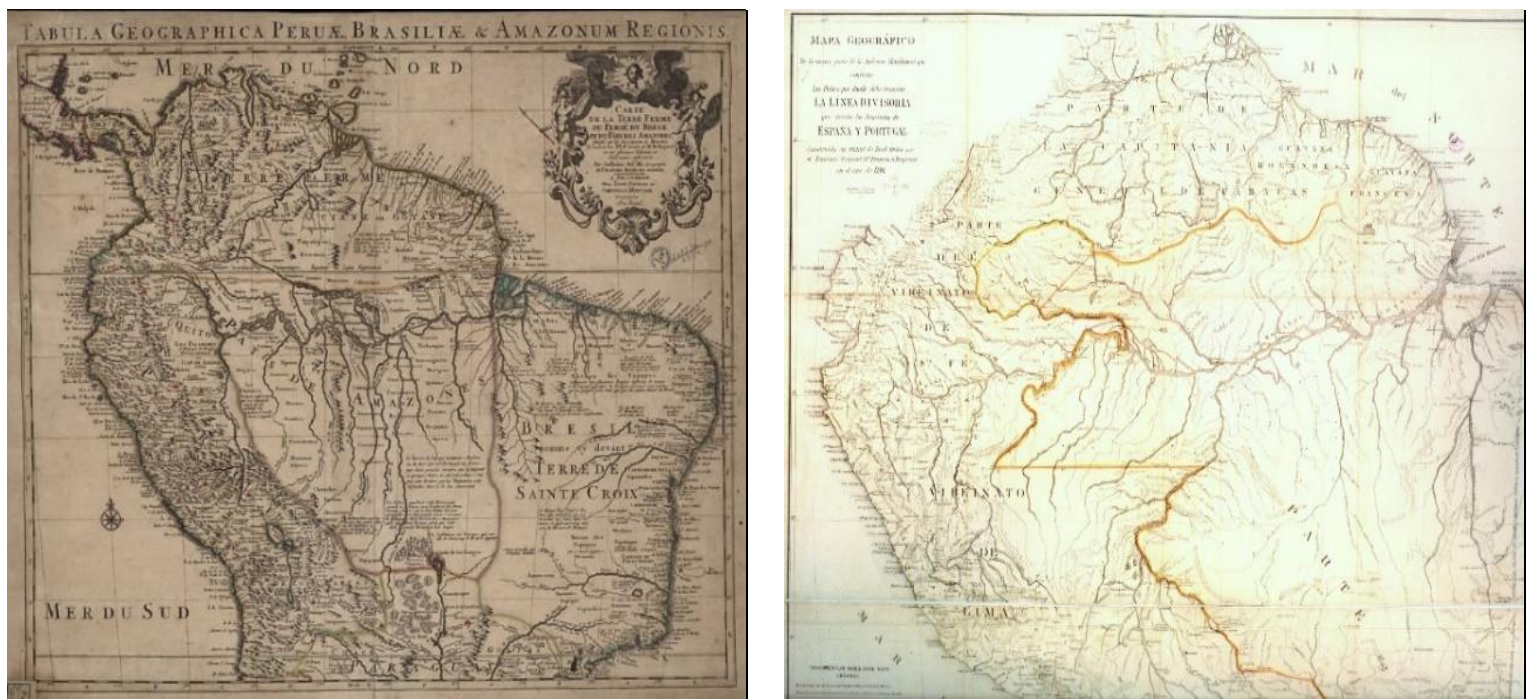

Fuente: www.wikimedia.org; www.wikipedia.org

\section{EL ALTO RÍO NEGRO - VAUPÉS, SU CONOCIMIENTO Y SUS MAPAS}

El acceso al río Vaupés se produjo después de 1725, tras la derrota militar propinada por la corona portuguesa a los indios Manaos (WRIGHT, 1981). Este hecho permitió la presencia de misiones carmelitas, que tras un período de actuación de 80 años en el río Negro dieron paso hacia la mitad del siglo XIX a una fugaz presencia de misioneros capuchinos y treinta años después a la presencia de misioneros franciscanos (CABRERA, 2002, p. 67-122).

Sobre el alto Río Negro-Vaupés, existe una cartografía que se remonta al siglo XVIII. En Colombia el Vaupés estuvo inalterado hasta 1965, cuando se creó el Departamento de Guainía y en 1977 el Departamento del Guaviare. En Brasil entre tanto el Alto Río Negro y su afluente el Vaupés hicieron parte de la Capitanía de São José do Rio Negro (1755-1823) y 
luego de llamada Comarca, Provincia y finalmente Estado do Amazonas, en este último durante el siglo XX como parte del hoy Municipio de São Gabriel da Cachoeira.

En el Alto río Negro-Vaupés, fronterizo entre Brasil y Colombia, residen unos 35 pueblos indígenas de filiaciones lingüísticas Tucano oriental, Arawak y Makú. Juntos conforman un complejo cultural en el que comparten la asociación mítica y ritual del Yuruparí pero que a su vez se diferencian en su nombre, lengua, ascendencia ancestral, propiedad de elementos rituales, historia mítica, desplazamiento primordial y territorialidad (CORREA, 1996, p. 12).

Los veinte pueblos de filiación Tucano oriental señalan su lugar de origen o casa de emergencia OhkóDiawi, localizada en el bajo río Vaupés (DUTRA, 2011, p. 235); conocida como la cueva de Tocandira, lugar donde la Anaconda ancestral habría celebrado el primer ritual de iniciación. Los "grupos habrían llegado hasta allí remontado un eje fluvial común” y "luego se habrían separado por diversos afluentes (CORREA, 1996, p. 223). En cuanto a los Arawak, son seis pueblos que señalan a Hipana, un raudal en el río Aiary, como su lugar de origen (WRIGHT, 1983, p. 538).

El multilingüismo y la exogamia lingüística son propios de los grupos de filiación Tucano oriental (SORENSEN, 1967; JACKSON, 1983) con la excepción de los Cubeo (GOLDMAN, 1968) y Makuna (ARHEM, 1991) cuyos grupos de descendencia están clasificados entre sí como hermanos o cuñados, de manera que entre los primeros no debe haber matrimonios; aunque actualmente entre los Cubeo y Makuna hay un relativo intercambio con grupos distintos (CORREA, 2000, p. 91).

Los pueblos Makú entre tanto, tienen una reconocida proximidad lingüística definida como la familia lingüística Makú-Puinave (RIVET y TASTEVIN, 1920) hoy se identifican como Nadahup un conjunto integrado por el Hupda, Yuhup, Daw y Nadeb (EPPS, 2008, p. 5) o también llamado Makú oriental, diferente al Makú occidental, integrado por el Kakua y Nukak (MARTINS, 2005).

La cartografía de la zona es tardía. La toponimia antigua en los mapas de la región amazónica deriva de la primera expedición descubridora que dio el nombre o del nombre consolidado en épocas tempranas, también existen denominaciones relacionadas al conquistador o a figuras de la antigüedad clásica griega como la bien conocida de las Amazonas (RABELO, 2015, p. 162).

El nombre Uaupés, fue inicialmente asociado a una denominación genérica de los indígenas del río del mismo nombre (WALLACE, 1992) o a un líder carismático en el curso del río Vaupés (AMORIM, 1943), aunque en verdad corresponde a un segmento de población 
indígena (ANDRELLO, 2006). Bajo su nombre se conoce una representación gráfica llamada el indio Uaupé (CABRERA, 2015).

Vaupés se escribió como Cajari por Ignacio Zsenmartonyi (1749); Ucayarí, Uacaiarí por José Monteiro de Norohonha (1768) Caiarý por Francisco Xavier Ribeiro de Sampaio (1774-1775). El río Vaupés es un afluente de la margen izquierda del Río Negro que nace de la unión de los ríos Unilla e Itilla en Colombia, corre sobre planicies sedimentarias terciarias y se le mezclan cursos de aguas negras, razón de su tonalidad intermedia (DOMÍNGUEZ, 1985, p. 76).

En el primer mapa de 1774 fue publicado por la historiadora brasileña Patricia Sampaio se aprecia el Rio Negro indicando que está aumentado hasta el paralelo de cinco grados de latitud boreal y que incluye las comunicaciones de los ríos Negro, Orinoco y Cavaburis.

En la porción del Alto Rio negro se aprecian San Joaquín, San Felipe, Santa Ana, Nuestra Señora da Guía, el fuerte San José de los portugueses y el fuerte San Carlos de los españoles. Por la margen izquierda se aprecia el río Isana y uno de sus afluentes el río Iquiari, más al sur se aprecia el río Vaupés. Al norte el brazo del Casiquiare que comunica el río Orinoco con el Río Negro cuyo conocimiento se remonta a 1744. (SAMPAIO, 2012, p. 350351). (Mapa 10).

Figura 6: O Estado e capitanías do Gram Pará e Rio Negro com as do Maranhão e Piauhy 1774

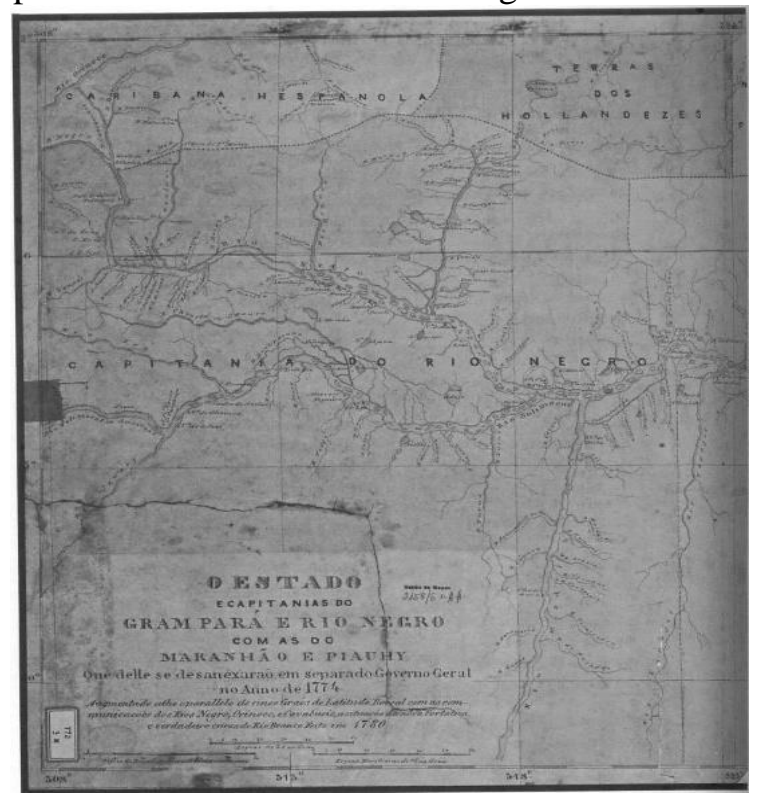

Fuente: Sampaio, 2012 
En 1782 se conocen los primeros mapas de la región ${ }^{3}$; que detallan la zona del rio Apaporis y fueron hechos por José Joaquim Victorio da Costa (ADONIAS, 1963, p. 136137). Pero son los mapas de Manoel da Gama Lobo D’almada (1745-1799) los primeros con el nombre del río Uaupés. Nacido en Urmeira, cerca de Lisboa, se educó como ingeniero militar especializado en cartografía (MEIRELLES, 2009, p. 67).

Fue nombrado en 1784 para adelantar trabajos cartográficos y de exploración en el Río Negro entre 1772 y 1780, realizó la tarea teniendo como base São Gabriel hasta 1786. Detalles sobre su itinerario y dificultades pueden seguirse en otros textos ${ }^{4}$ (ADONIAS, 1963, p. 141-143; BITTENCOURT, 1973, p. 326; CABRERA, 2002, p. 90-92; REIS 2006).

D'almada hizo cinco mapas (REIS, 2006). Con su trabajo estableció la existencia de comunicaciones entre el Uaupés [Vaupés] y Japurá [Caquetá]. Dos mapas de D’almada fueron tempranamente publicados (ROQUE, 1967, p. 605) y reproducidos luego en otros dos trabajos (ISA, 2006, p. 81; CABRERA, 2002, p. 91).

Estos mapas fueron copiados en 1844 por Luis Antônio da Silva Beltrao. Estos dos mapas y los otros tres de D'almada permiten identificar asentamientos en la zona, fortalezas portuguesas y españolas, ríos y afluentes, obstáculos naturales o cachiveras, pasos terrestres y algunos de los grupos indígenas como Ananas y Manibas que corresponden a los nombres actuales de Wanano y Baniwa en la zona del río Vaupés o Curetús, estos últimos referidos por Alexandre Rodrigues Ferreira y Alfred Wallace como habitantes del río Apaporis.

Un elemento grafico que vale la pena mencionar en los mapas producidos por d'Almada es la presencia en ellos de la rosa de los vientos que como indica otro investigador junto al cuadrante y el astrolabio son "símbolos de autoridad y precisión" (NIETO, 2010, p. 13). Es decir intentan conferir cientificidad a la representación cartográfica. El Cuadro 5 compara los mapas del río Vaupés y el Cuadro 6 los mapas de las comunicaciones en el río Negro.

Hay dos mapas elaborados bajo los trabajos de la Comisión Corográfica que se adelantó entre 1850 y 1859 bajo la dirección de Agustín Codazzi, quien a pesar que no recorrió la zona, incluyen valiosas anotaciones relacionadas con la presencia española o portuguesa, los pueblos indígenas, los caminos y algunas cifras de población.

Pese a que su escala no es legible y ambas cartas no coinciden exactamente las notas si lo son. Su contenido debe acompañarse de la lectura de la Descripción del Territorio del Caquetá fechada en 1857 (DOMÍNGUEZ, GÓMEZ y BARONA, 1996, p. 149-252). Codazzi

\footnotetext{
${ }^{3}$ Ref: 109, 110, 112, 113,114, 115, 123, 127.

4 cf. ROQUE, 1970-1971, p. 604-607.
} 
viajó por un área próxima en compañía de su hijo Domingo, el ingeniero militar y acuarelista Manuel María Paz (1820-1902) y contó con el apoyo de Miguel y Pedro Mosquera, dos comerciantes locales y funcionarios públicos de la región como con un indio anónimo reducido (DOMÍNGUEZ, GÓMEZ y BARONA, 1996, p. 170 cf. APPELBAUM, 2017, p. 173).

Sin embargo, pese a la calidad de la información recopilada "la Comisión Corográfica fortaleció el sentido de región más que el de nación" (TOVAR, 2009b, p. 21). El Cuadro 7 muestra los mapas y la ilustración de Paz de sus colaboradores.

Figura 7: Comparativo Mapas 11 y 12. Communicação do Rio Uaupés para o Japurá, pelo Rio Yucari, ou Pururéparaná (1785) y Mapa das comunicações do Rio Negro para o Japurá de Lobo D'almada

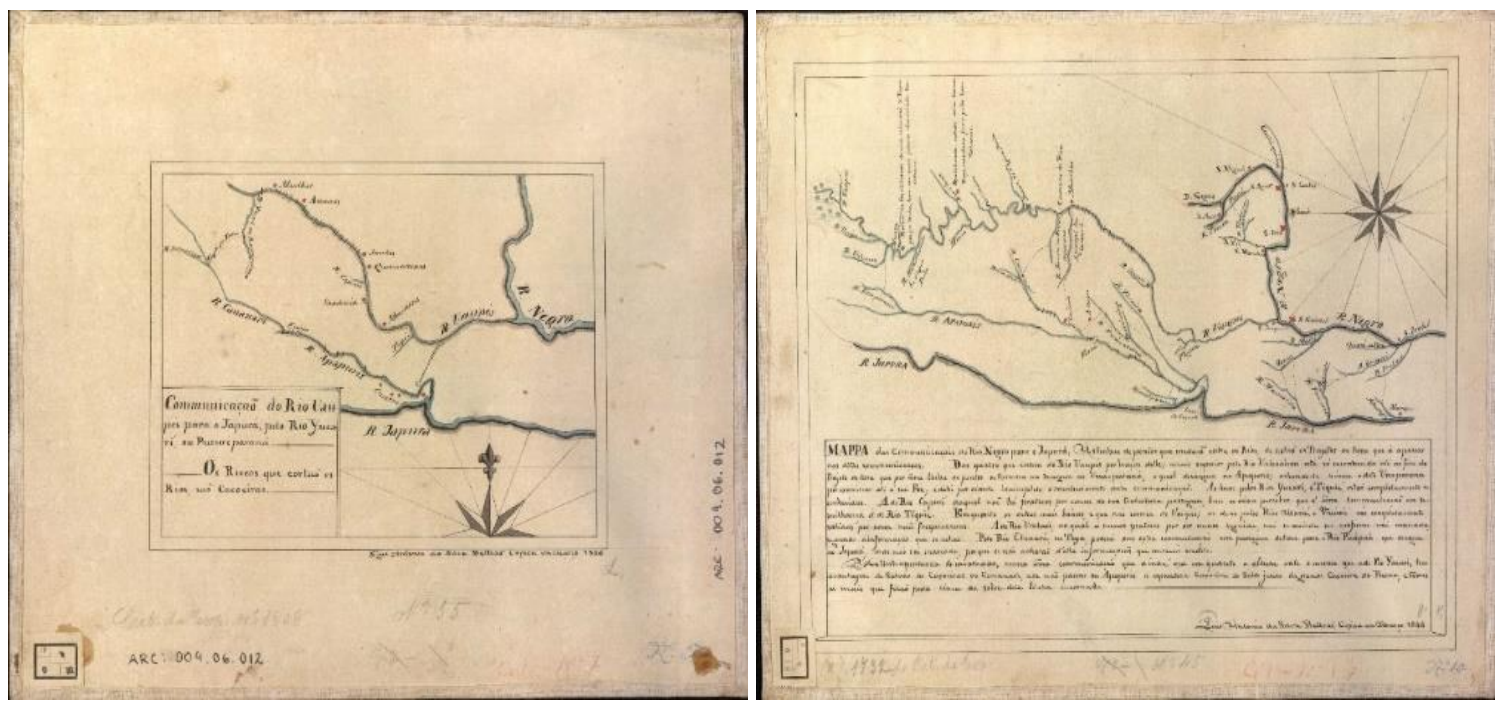

Fuente: AHU_CARTm_020, D. 0776 y AHU_CARTm_020, D. 0778

Figura 8: Comparativo Mapas 13 y 14. Comunicaçons do Río Negro para o Japurá por três bocas superiores y Mappa en que se demostrao duas comunicações do Rio Uaupés pra o Japurá de Lobo D'almada
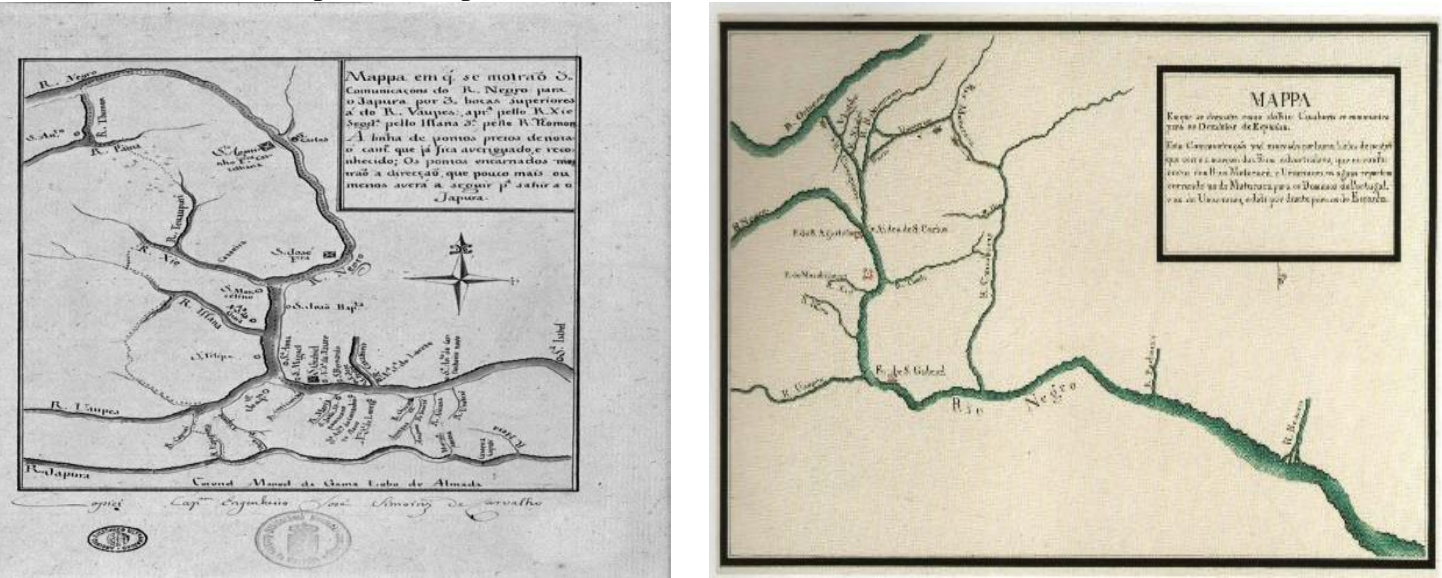

Fuente: AHU_CARTm_020, D. 0775 y AHU (sin identificar) 
Figura 9: Mapa em que se demostrão duas cummonicaçoens do Rio Uaupés para o Japurá, pelo Rio Yucari, e pelo Tiquié

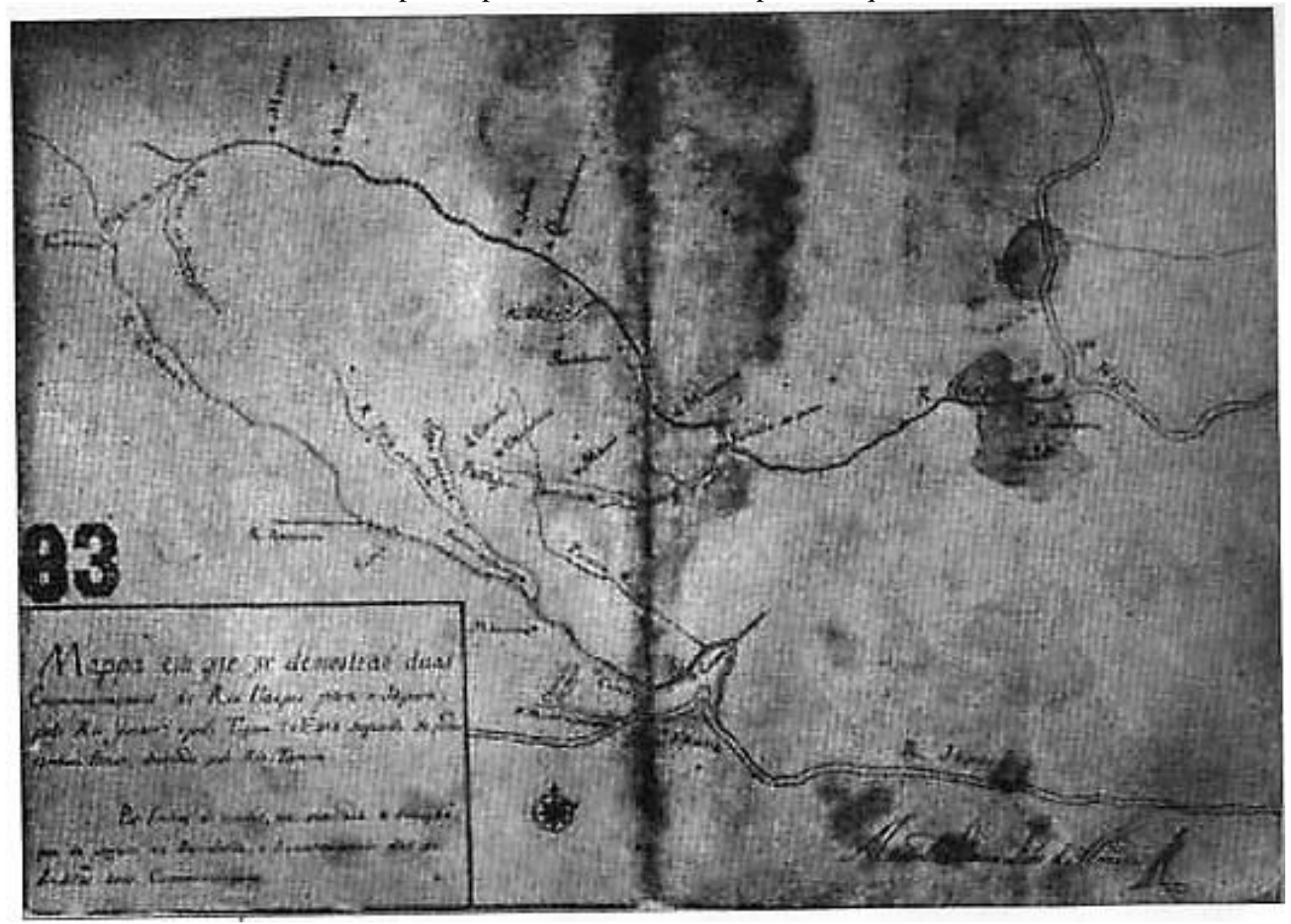

Fuente: AHU_CARTm_020, D. 0777

Figura 10: Mapas 16 y 17 de Agustín Codazzi. Región del Alto Orinoco- Rio Negro y Caquetá o Japurá y río Putumayo y su desembocadura en el Amazonas e imagen de sus colaboradores
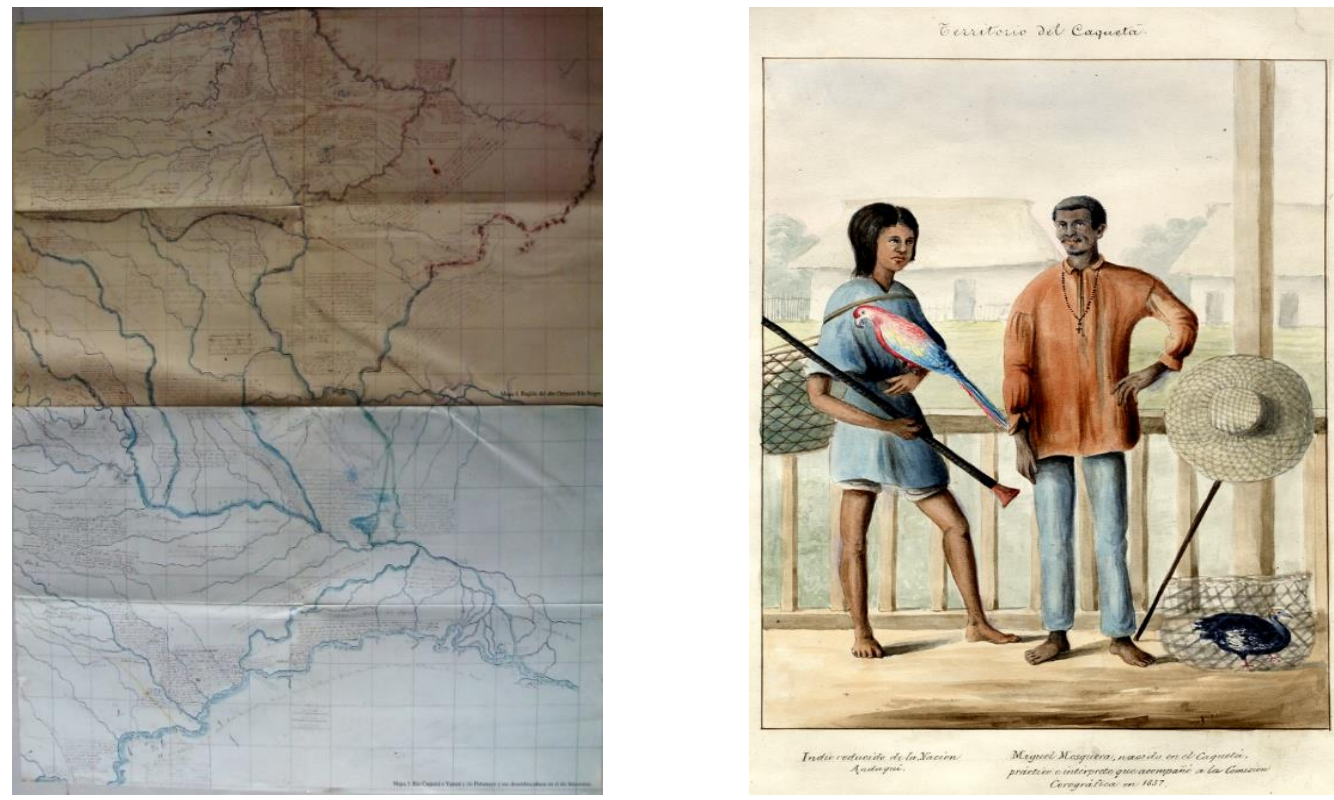

Fuentes: Domínguez, Gómez y Barona, 1996 
Otros mapas generales son de dos pioneros en penetrar el río Vaupés. Alfred Russell Wallace (1823-1913) y Richard Spruce (1817-1893). Wallace ascendió por el río en dos ocasiones, una de ellas hasta proximidades del raudal Yuruparí, describiendo por primera vez el ritual que tiene el mismo nombre (WALLACE, 1992, p. 245-246). Spruce llegó hasta Yavareté para luego penetrar brevemente en el río Papurí, en esta zona experimentó y relató los efectos del yagé entre los indígenas (SPRUCE, 1996). Sus obras además incluyen dibujos de tipos indígenas, lugares y petroglifos.

En el siglo XIX el viajero francés Henri Coudreau (1859-1899) realizó varios viajes por la Amazonia, recorriendo la Guyana francesa y ríos como el Amazonas, Esequibo, Branco, Negro, Vaupés, Trombetas, Tapajós, Xingú y Tocantins. Los relatos de sus viajes, al Tapajós y al Xingú los hizo estando al servicio del Gobierno del Estado de Pará (COSTA, 2013, p. 20).

El itinerario de su viaje al Vaupés y sus informes sobre la actuación franciscana se detallan en otro trabajo (CABRERA, 2002, p. 107-116). Panoré fue el punto extremo de su viaje haciendo desde allí visitas hasta Taraquá. Su mapa fue publicado en una obra no citada por los estudios de la región el (COUDREAU, 1887). En realidad son cuatro mapas en escalas diferentes y en los que se ubican tres tipos de lugares sitios firmes, aldeas propuestas de casas y aldeas hechas de casas.

Figura 11: Mapa 18. Rios Negro et Uaupes

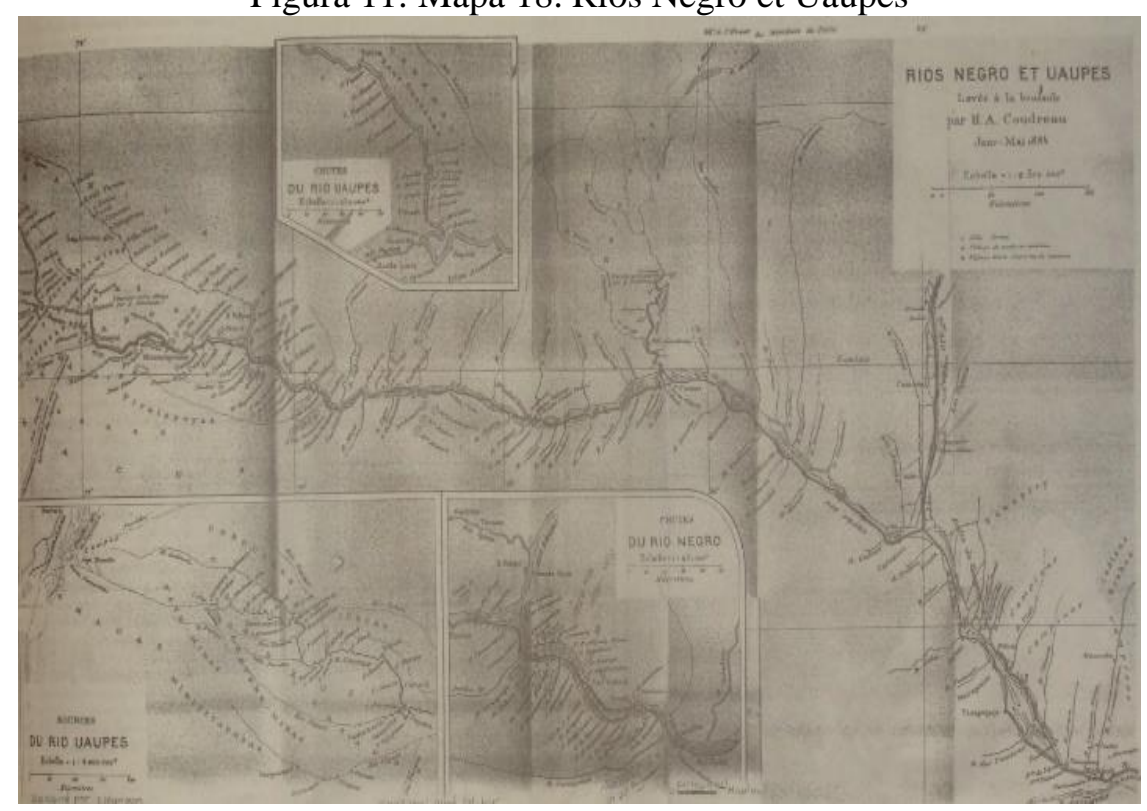

Fuente: Coudreau, 1887 
El italiano Ermanno Stradelli (1852-1926) hizo su primer viaje por el río Vaupés en 1881, recorriendo también los ríos Tiquié y Japu. En 1882, tras haber recorrido el río Branco, inició su segundo viaje por el Vaupés, y en esta ocasión alcanzó a remontarlo hasta Yavareté. Stradelli hizo tres mapas: Rio Branco (1888), Río Vaupés (1890) y Estado del Amazónas (1901). El segundo detalla el río y sus afluentes en dos segmentos; la parte alta por el norte el río Kerary [Querarí] y por el sur el río Apopory [Papurí], ambos ubican las sierras, afluentes por los dos márgenes con sus nombres y las cachiveras (Mapa 19).

El tercer mapa, relaciona una veintena fuentes consultadas ubicando sierras, cachiveras, las antiguas misiones y fortalezas. Los cursos de los ríos principales están en color azul y los límites internacionales con un trazo continuo rojo. Este mapa fue adquirido por el gobierno del Estado del Amazonas para uso didáctico en las escuelas elementales y secundarias; en el mismo algunas zonas como el Madeira, Purus y Solimões hay imprecisiones debidas probablemente a desacuerdos en las fuentes consultadas (FONTANA, 2006, p. 48-51). Ver Cuadro 8.

Otros mapas son del viajero alemán Theodor Koch-Grünberg (1872-1924). Él viajó por el río Xingú (1888/1889), por el Negro y Caquetá (1903 a 1905), por el Branco y Orinoco (1911/1913). La edición Dos años entre los indios (original alemán de1909), incluye un mapa de los ríos Negros y Japurá, ubicando poblados indígenas, asentamientos y cachiveras.

Además se incluye los nombres de los pueblos. Un segundo mapa es de los petroglifos en el noroeste (1907) que ubica 29: 6 en el río Cuduyarí, 14 en el Aiary, 2 en el Tiquié, 1 en el Curicuriary, 1 en el Pira-Paraná y los otros 15 en el río Vaupés (KOCH-GRÜNBERG, 2010). Con una base cartográfica similar al anterior la ubicación hay otro mapa con 43 sitios en los que Koch-Grünberg hizo hallazgos minerales. Las materiales de Koch-Grünberg fueron donados por su nieta al Departamento de Antropología de la Universidad de Marburg y se sabe que existen aún otros mapas inéditos (CABRERA, 2018a, p. 161). 
Figura 12: Mapas 19 y 20 de Stradelli. Uaupés (Caiary, Bopé, De Boopé) 1890-91 y Mappa Geographico do Estado do Amazonas. 1901
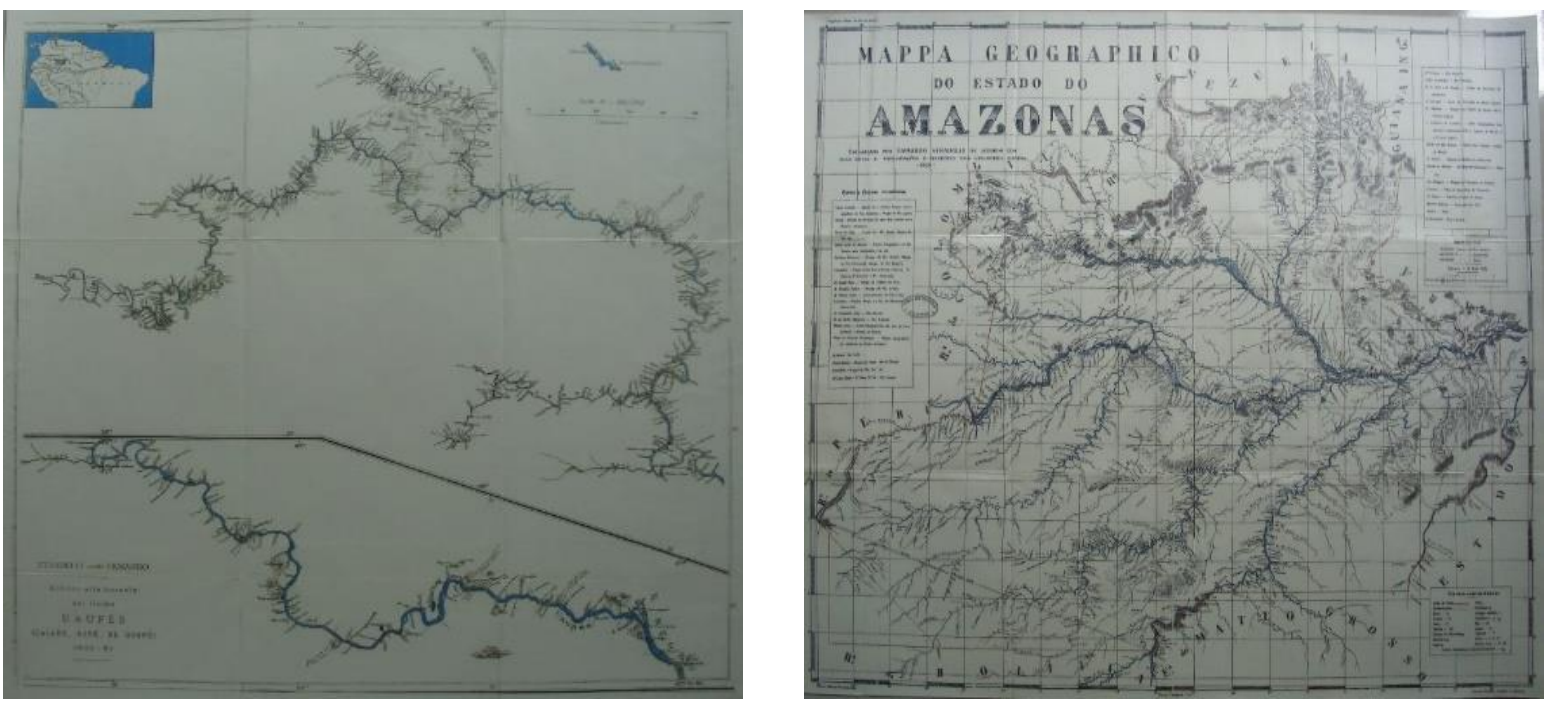

Fuente: Fontana, 2006

Mapas adicionales son del médico norteamericano Hamilton Rice (1875-1956). Rice hizo tres expediciones en la región central del Noroeste Amazónico, cuyo itinerario se detalla en otro trabajo (CABRERA, 2002, p. 144-146). Estos son: The River Uaupés (1907-1908); The N. W. Amazon Basin (1907-1908 y 1912-1913); Survey of the Rio Negro from Manaos to Sao Gabriel (1917) y The Upper Rio Negro, Casiquiare canal and the Upper Orinoco (19191920).

En ellos se ubican los pueblos indígenas, las sierras, cachiveras, viviendas indígenas, campamentos caucheros, límites navegables y asentamientos. Además se diferencia la altitud. Como ejemplo incluyo a continuación el primero de estos. El Cuadro 9 muestra dos ejemplos de los mapas del siglo xx.

Otros cinco mapas son de los trabajos de la Inspeção de fronteiras que en 1928 hizo una expedición a los límites entre Colombia y Venezuela comandada por el mayor Boanerges Lopes de Souza (1881-1961). Los cuatro primeiros son: Carta ethnographica das Bacias dos Rios Içana e Uaupés ou Caiary; Rio Uaupés e seus afluentes Tiquie e Papory; Rio Içana e seus afluentes Aiary e Cuiary; Trecho do Rio Negro e seu afluente Xié y um quinto mapa es Trecho da Carta organizada pela Comissão Rondon.

Estos mapas son muy detallados pues muestran una gran cantidad de igarapés afluentes de los cursos principales de agua con sus respectivos nombres, además ubican las cachiveras, los pasos terrestres y se acompañan de su respectiva escala. La Carta etnográfica de las cuencas de los ríos Isana y Vaupés o Caiary aunque no tiene el mismo nivel de detalle 
de los igarapes de los anteriores si ubica nominalmente a los diversos pueblos de la zona y se acompaña de los trazos de unas flechas que indican las áreas de influencia o por donde se mueven los diversos pueblos (SOUZA, 1959).

Figura 13: Mapas 21 y 22. Fundorte von Felszichnungen de Theodor Koch-Grünberg y The River

Uaupés, oct 1907-apr 1908 de Hamilton Rice
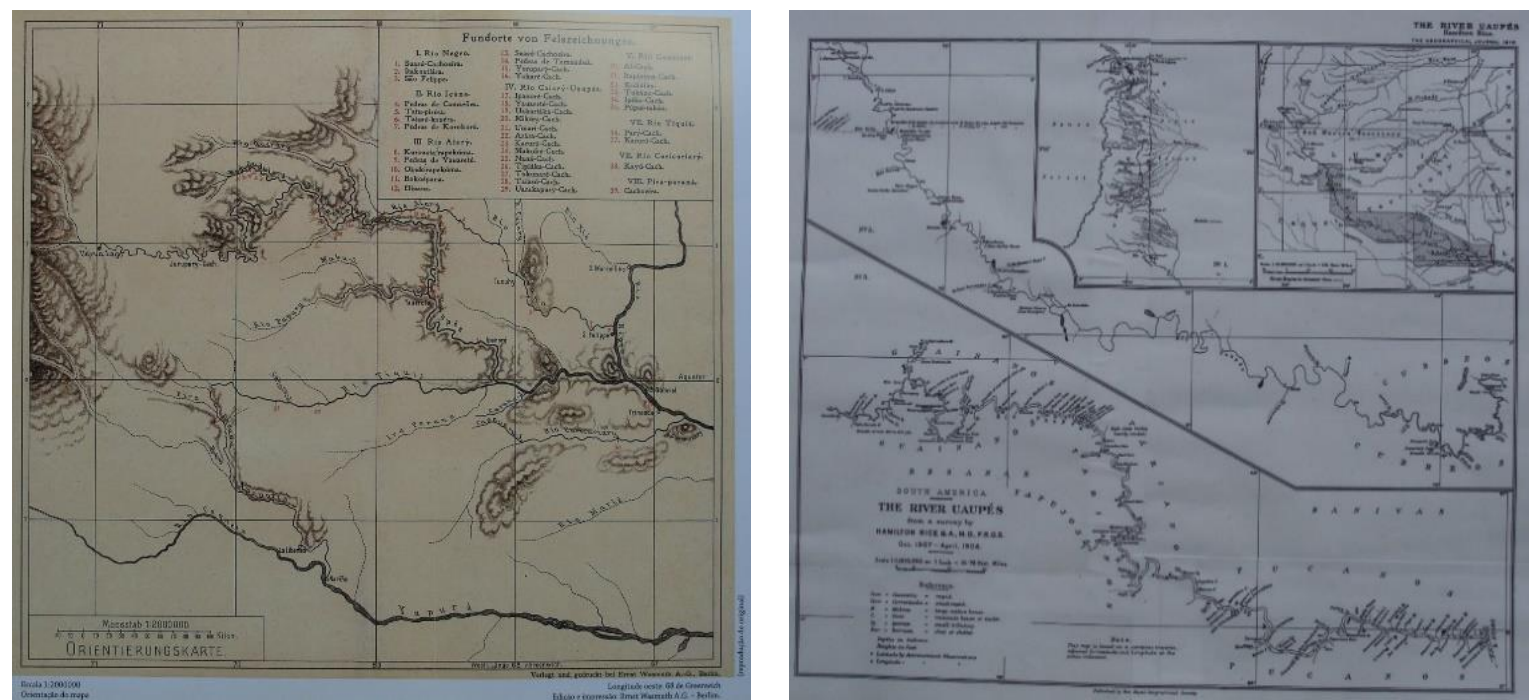

Fuentes: Koch-Grünberg, 2010; Rice, 1910

Figura 14: Mapa 23. Carta ethnographica das Bacias dos Rios Içana e Uaupés ou Caiary

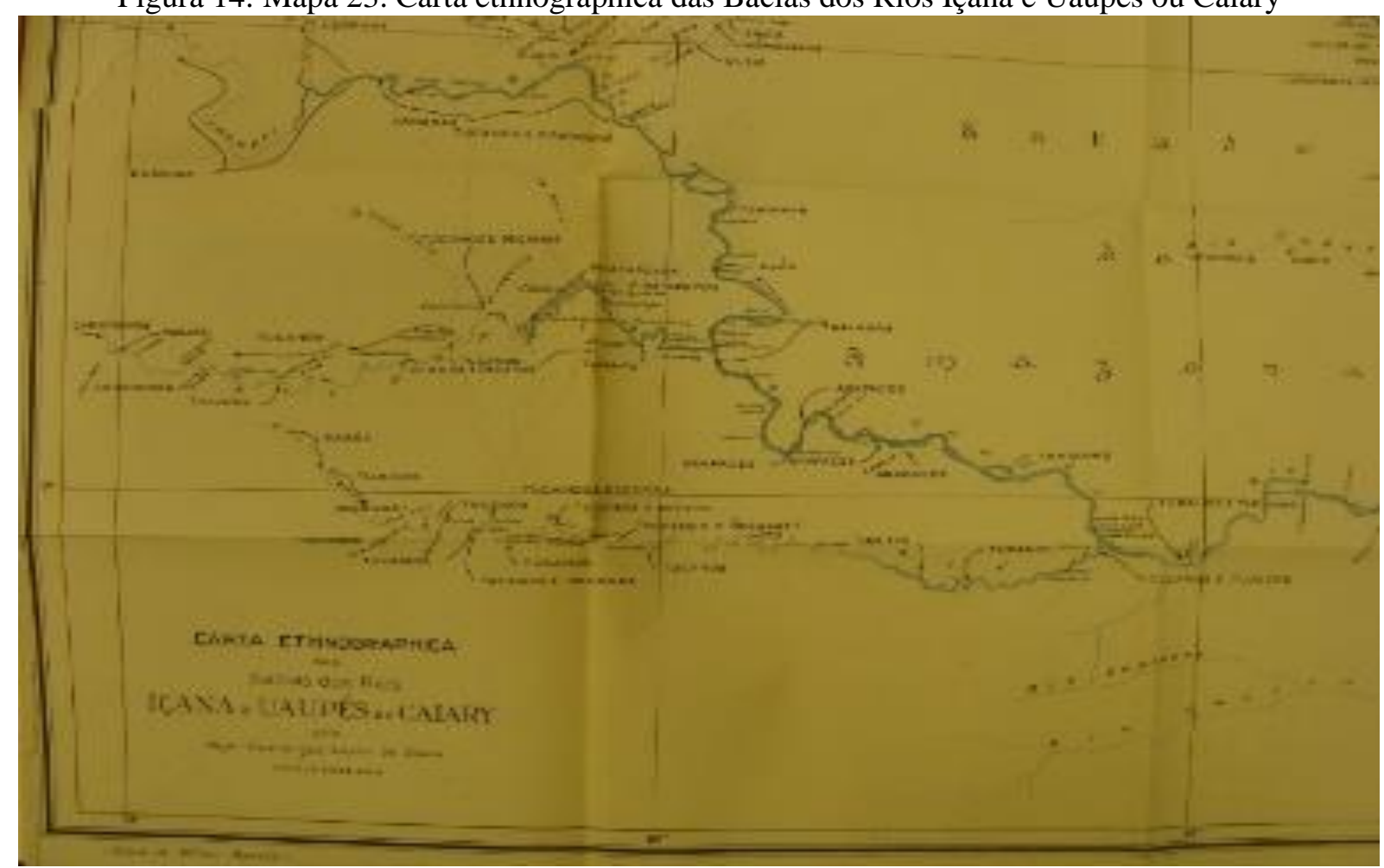

Fuente: Sousa, 1959 
Existen dos mapas de los misioneros monfortianos que trabajaron en el Vaupés colombiano de 1914 a 1949. El primero ubica las reducciones de Santa María en el río Cuduyary, Monfort en el río Papurí y tres localidades más en el río Vaupés (Urania, Elvecia y Circasia). Sobre el río Papurí se ubican también San Pablo, distante medio día de San José a un día descendiendo desde San Bernardo y San Francisco Javier, sobre el río Cuyucuyu se ubica a San Bernardo. Aunque inicialmente el poblado de San José fue ocupado por Tucanos luego se sumaron Tuyucas, San Pablo era un pueblo de Tucanos y San Bernardo de los Desanas, San Javier de los Pira-tapuyo.

Un segundo mapa fue publicado por el misionero Pedro Kok, el más destacado en la región (CABRERA, 2019). Este detalla la toponimia indígena, los afluentes del río y la distribución de los pueblos indígenas en ambas márgenes del río. Ubica cuatro poblados: San Raúl, Santa Rosa, Santa María y San Humberto.

De los tres primeros no existe ninguna información, pero se sabe que para 1944 Santa Rosa y Santa María habían desaparecido. San Humberto se encontraba aguas arriba de San Pablo y había sido fundado en 1919. Sus moradores lo abandonaron poco tiempo después, debido a rumores propagados por los blancos, quienes alertaban sobre el ataque de unos indios bravos, o el posible traslado que los misioneros harían de los niños de sus escuelas hacia Bogotá (CABRERA, 2002, p. 194). El Cuadro 5 permite visualizar los mapas monfortianos.

Figura 15: Mapas 24 y 25. Colombia: Misión del Vaupés e Indígenas en el río Papurí y sus afluentes
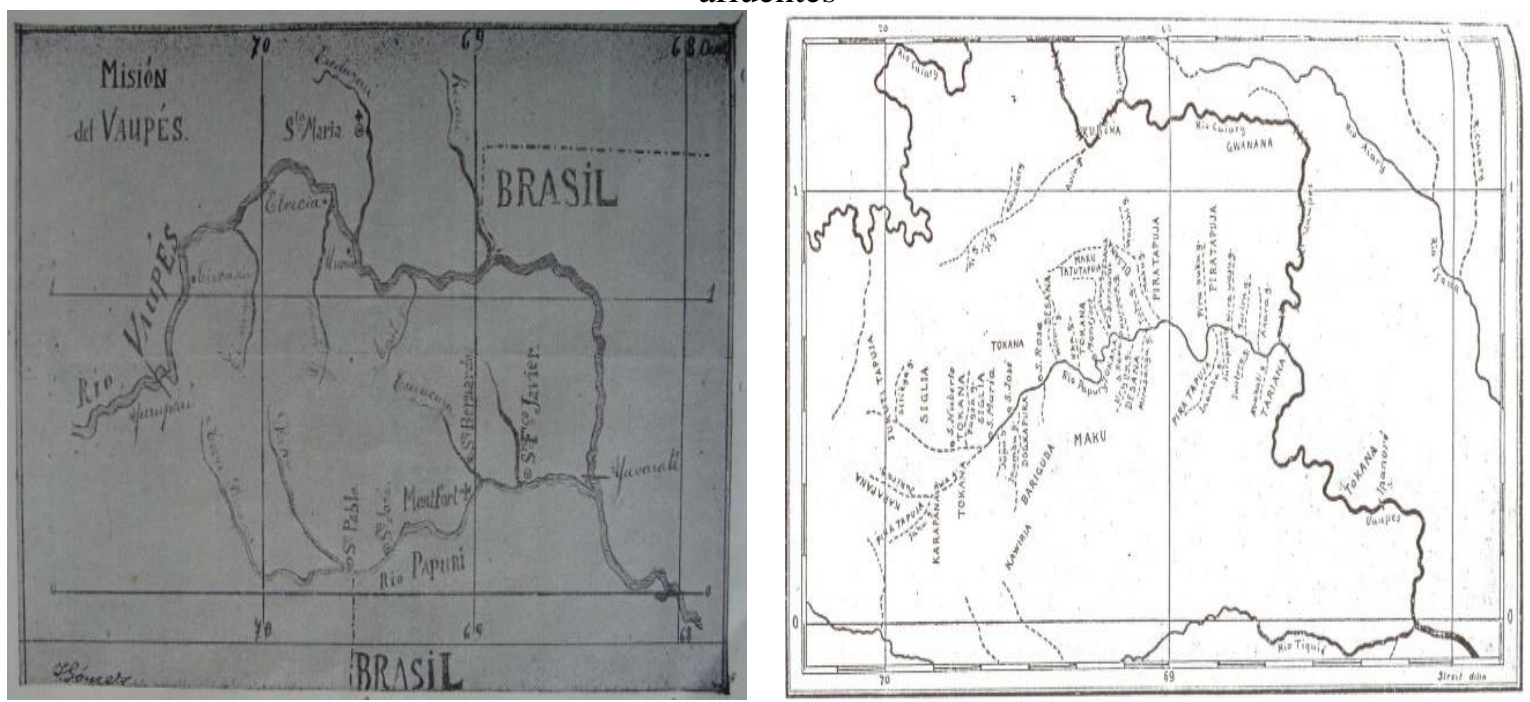

Fuentes: Damoiseaux, 1923; Kok, 1925 
En la Monografía inédita de la Comisaría del Vaupés colombiano del ingeniero Agrónomo Félix M. Díaz Galindo de 1935, se incluye el mapa Gráfico agrícola de la Comisaría del Vaupés colombiana que muestra las zonas de ubicación explotación de recursos como Tagua, Piaxaba, Castaña, Sarrapia. Igualmente, ubica las malocas indígenas (triángulos) y las casas de blancos (cuadrados), aduanas necesarias, pretensiones brasileñas (flechas relámpago en rojo), trochas existentes (línea de rallas rojas) y vías que se aconsejan (línea de puntos y rallas rojas), uno de cuyos segmentos reproduzco como Mapa 26.

Figura 15: Mapa 26. Segmento del Gráfico Agrícola de la Comisaría del Vaupés. Félix M. Díaz Galindo. Ingeniero Agrónomo. 1935

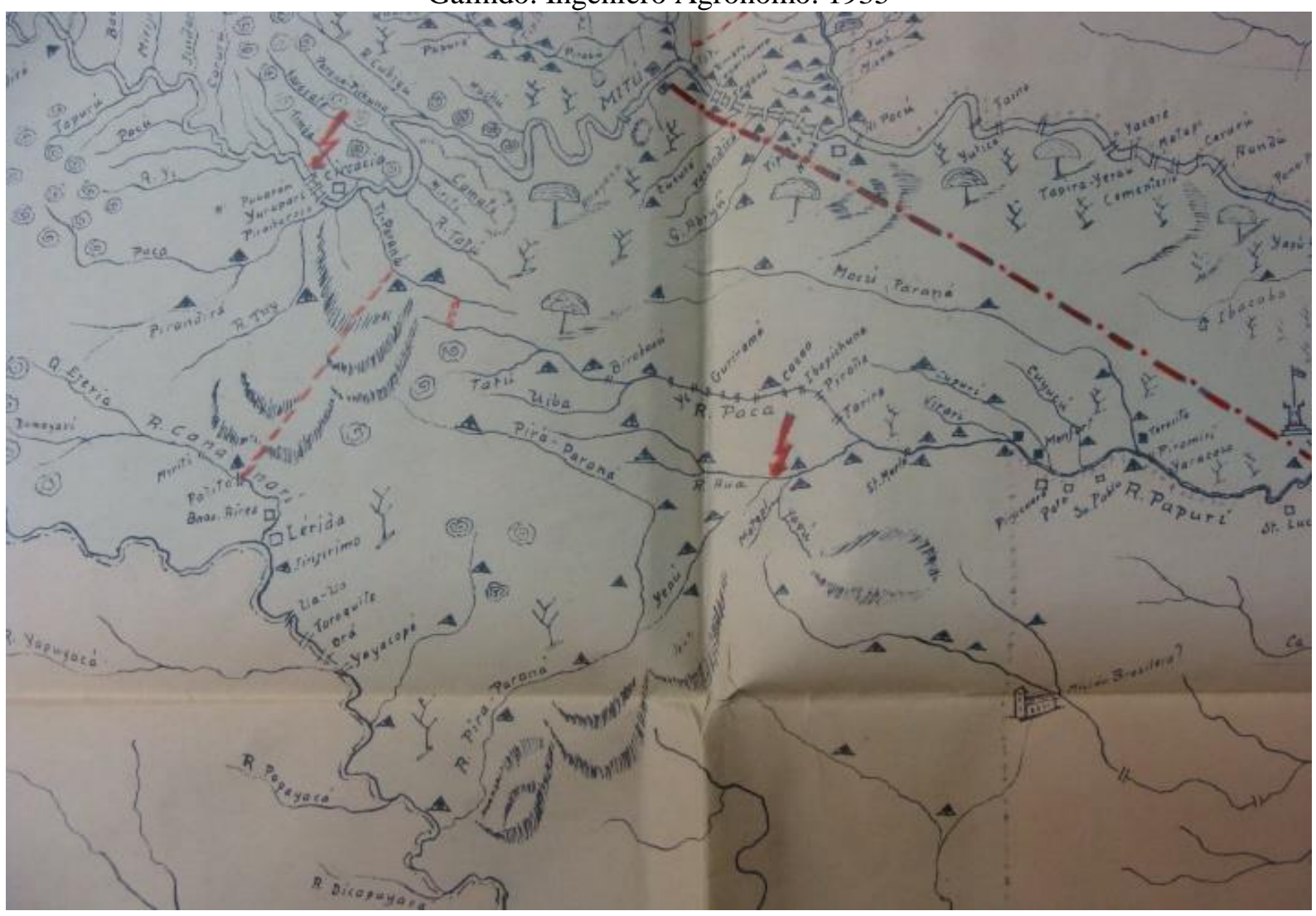

Fuente: Biblioteca Luis Ángel Arango. Sala Raros y Manuscritos

La Oficina de Longitudes adscrita al Ministerio de Relaciones Exteriores hizo en 1941 una carta geográfica levantada para detallar los hitos internacionales, basada en los trabajos de las comisiones mixtas de límites con Venezuela y Brasil y en los planos levantados por algunos exploradores. En ella se detallan los asentamientos existentes. Otro mapa es el de la Intendencia del Amazonas publicado por la policía nacional. Sí bien el mismo no es del Vaupés, en la parte norte se aprecia una porción de la Comisaría del Vaupés que ubica 
algunos pueblos indígenas como Ofaina [Ufaina], Datunas, Idulia [Edulia], Makú, Yukunas, la base cauchera de Campoamor en el bajo Mirití y el internado del Mirití.

\section{LOS MAPAS DEL RÍO PIRÁ-PARANÁ}

Los mapas del río Pirá-paraná permiten seguir una zona con detalle. Conocido tardíamente, se considera la zona donde están mejor conservadas las tradiciones de los pueblos de la región. La expedición de J. G. Eberhard en la segunda mitad de la década del cincuenta suministro datos iniciales. Después lo exploró el misionero Manuel María Elorza en 1959 y luego los británicos Brian Moser y Donald Tyler (CABRERA, 2016).

El aislamiento del Pirá-paraná obedece a su distancia y a los raudales que dificultan la navegación. Adicionalmente, en la tradición oral de los Tucano se mencionan confrontaciones entre sus moradores y los Tucano del río Tiquié, donde los últimos vencieron a los primeros antes de la presencia franciscana de la década de 1880. Estas fricciones contribuyeron al aislamiento y "todavía hoy, los Tucano del río Tiquié recelan de viajar para el Pirá-Paraná, recordando las antiguas hostilidades" (GENTIL, 2005, p. 56).

En el siglo XX las fricciones con los caucheros llevaron al repliegue de los indígenas, quienes retrasaron cualquier ingreso de los blancos al río donde "con frecuencia fueron muertos por los habitantes" (MOSER; TYLER, 1963, p. 442). Un indicador adicional lo suministraba el misionero Francisco Arango al señalar en uno de sus mapas fechado en 1971 que en la zona el entendimiento del español era de un $90 \%$ en el río Papurí y de un $10 \%$ en el río Pirá-Paraná" lo que ratifica su relativo aislamiento.

Moser y Tyler (1963) hicieron un mapa ubicando malocas, casas de blancos, viejos sitios, petroglifos, raudales, caños y trochas. Las alturas fueron ajustadas con base en la carta aeronáutica mundial y las distancias y cursos del Apaporis, Miritiparaná y Caquetá fueron estimados según el tipo y la ruta del viaje.

El mapa incluye información de carácter geológico suministrando un perfil para los ríos Ti y Pirá-paraná. Un segundo mapa de este río es más tardío y fue elaborado por un misionero Javier. Este muestra una porción del río sus afluentes, indicando las rutas hacia donde conducen, el lugar de la misión y algunas de las malocas con el nombre de su líder (Paulino, Rufino, Domingo y Sabino). En la parte norte se traza el varador que une las cabeceras del río Pira-Paraná con el caño Ti que desemboca en el Vaupés (ALMAS, 1976 p. 7). Ver Cuadro 11.

Dos mapas más fueron elaborados por el misionero Francisco Arango Montoya (19312007). El primero no tiene fecha ni escala, y muestra con mucho detalle la ubicación de las 
malocas en los afluentes por la margen izquierda y derecha del río, al igual que la ubicación de las misiones del Instituto Lingüístico de Verano en el caño Utuya en la que trabajaron con los Tatuyo los esposos David y Janice Whisler entre 1969 y 1986 y los esposos Mark y Paula Bostrom entre 1995 y 2000 y la otra misión se ubica en el caño Comeñá en la que trabajaron con los Makuna los esposos Geoffrey y Josephin Smotherman entre 1970 y 1993 (CABRERA, 2015, p. 259-260).

Es decir el mapa fue elaborado con posterioridad a 1970 cuando ya existían las bases. El segundo mapa muestra las vías de acceso al Pirá-Paraná consistente básicamente en tramos a pie que se marcan con líneas punteadas y que suelen unir el curso de algunos de los caños de la región. El Cuadro 12 permite ver la distribución étnica y las comunicaciones en el mismo río.

Figuras 16: Mapas 27 y 28. Río Pirá-Paraná de Moser y Tayler y Región del Pirá-Paraná (anónimo).
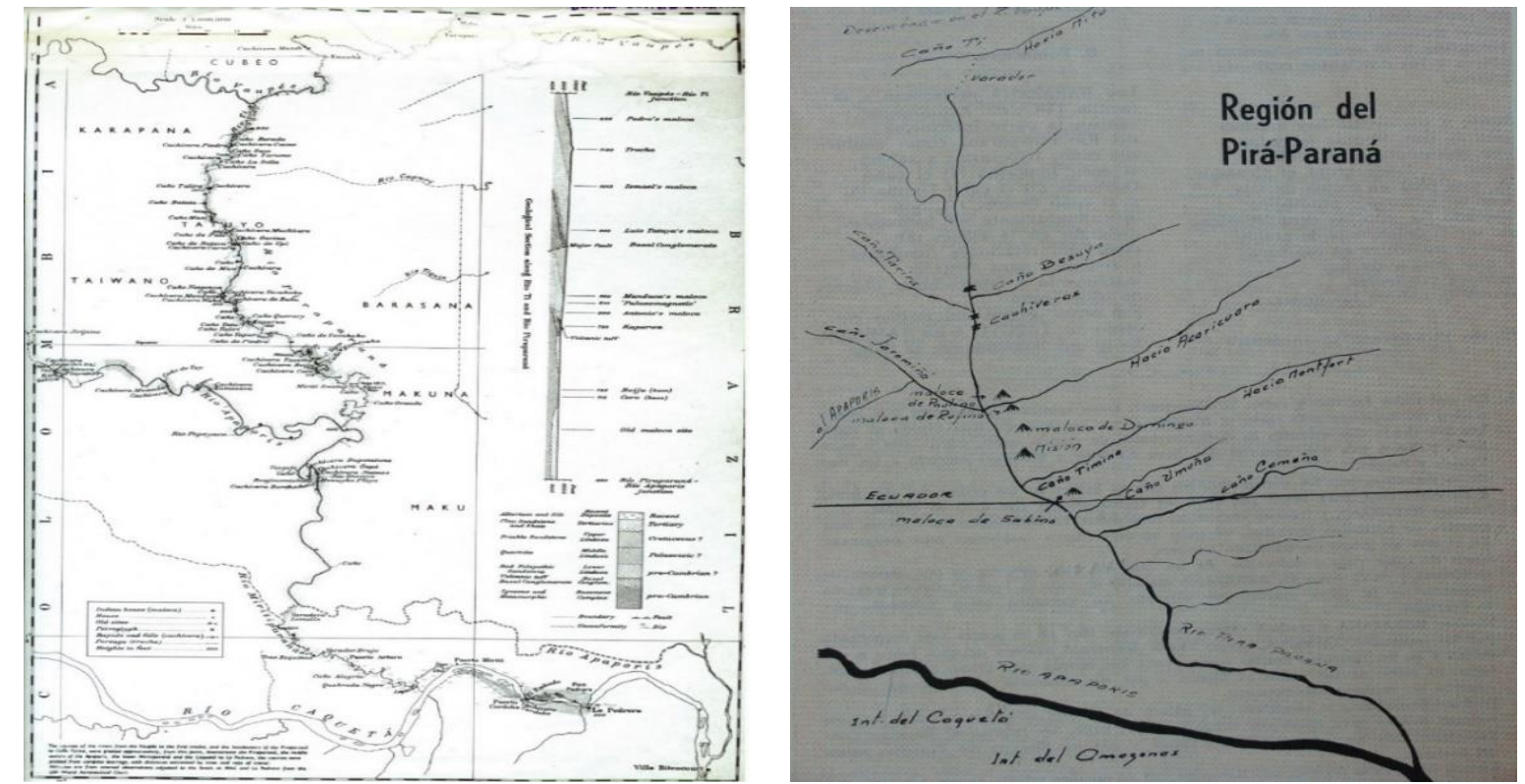

Fuentes: Moser; Tyler, 1963; Almas, 1976

\section{CONCLUSIÓN}

La cartografía que se conoce del Alto Río Negro-Vaupés comienza en el siglo XVIII y en su conjunto revela una característica ya señalada pues en ella están ausentes elementos artísticos y su elaboración atiende más a un propósito cada vez más científico que atiende a la medición de las distancias como rasgo particular, es decir a una orientación, la inclusión de una escala y la distinción cada vez mayor de rasgos del territorio (CABEZAS, 2015, p. 27; LÓPEZ, 2015, p. 57; SOUTO, 2017, p. 828). En todos los mapas del siglo xix hay escalas y 
un examen sesudo permite leer la espacialidad de los pueblos indígenas y los asentamientos existentes, los nombres de los cursos de agua, la ubicación de las cachiveras, los pasos terrestres, la distribución de los pueblos indígenas, etc.

Pero cierto es también que la temprana y gran mayoría de la cartografía aquí reunida fue elaborada por el imperio brasileño y muy tardíamente por Colombia, este es un claro indicador del interés político por sus fronteras, como de la capacidad de exploración, circunstancia que revela un desbalance con relación a Colombia que no tuvo igual desarrollo. Los mapas son instrumento que promueven "la eficiencia del Estado" y expresan "la voz del poder centralizado" (HARLEY, 2005, p. 130-131). Pero en la zona de este estudio la presencia en el siglo XX de agentes foráneos de importancia fueron los misioneros católicos, pero hay un gran contraste.

Figura 17: Cuadro 12 - Mapas 29 y 30. Lenguas que se hablan en el Pirá-Paraná y Rutas de acceso al
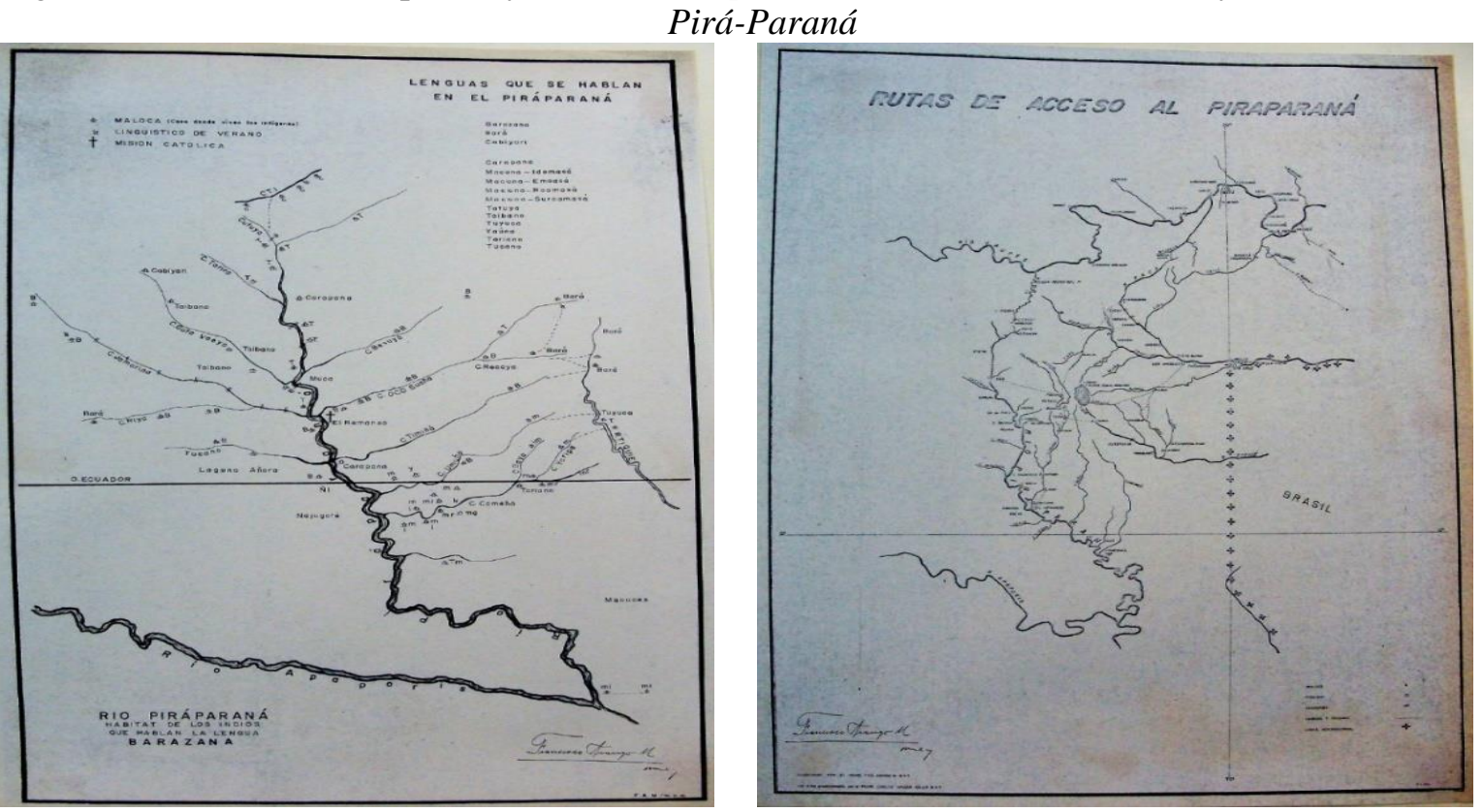

Fuente: Archivo Biblioteca del Seminario

Javieres de Yarumal

Algunos de los misioneros salesianos provenientes de Italia, que trabajan en la zona desde 1914 hasta hoy en Brasil, hicieron significativos aportes a la etnografía y lingüística de la región, basta recordar los nombres de Alcionilio Bruzzi Alves da Silva, Antonio Giacone, Casimiro Beksta (CABRERA, 2015, p. 152-156). Entre tanto en Colombia los monfortianos provenientes de Francia que trabajaron entre 1914 y 1949 tuvieron en el padre Pedro Kok una 
figura destacada que dejó trabajos lingüísticos y uno de los mapas (CABRERA, 2019). Pero es entre los javieres de Yarumal, que trabajan desde 1949 hasta hoy, que la elaboración de mapas tuvo en el misionero Francisco Arango Montoya una gran contribución que quedó plasmada en mapas inéditos y en una obra (ARANGO, 1977).

Con relación a la zona del Alto Río Negro - Vaupés fueron los exploradores y viajeros desde el territorio de Brasil quienes produjeron los primeros mapas. Ya avanzado el siglo XX las instituciones gubernamentales preocupadas por refinar el conocimiento de las fronteras, el comercio, la administración interna, el control de población y la fuerza militar como preocupaciones esenciales aparecieron en ambos países hacia la década del treinta.

En el siglo XXI y bajo la premisa de la continuidad biogeográfica y cultural de la región del Alto Río Negro - Vaupés dos nuevos desarrollos cartográficos que involucran esfuerzos multinacionales. Bajo la Red Amazónica de Información Sociambiental Georeferenciada trabaja en la elaboración de nuevos mapas que registran las amenazas de actividades dirigidas hacia la amazonia como carreteras, extracción de petróleo y gas, minería, construcción de hidroeléctricas, quemas y deforestación de gran importancia para orientar la toma de decisiones sobre la conservación de la Amazonia (RAISG, 2012). Con la participación directa de los indígenas la espacialidad de sus territorios, su toponimia y valor simbólico se ha plasmado en una cartografía de los sitios de valor cultural (CARTOGRAFÍA DE LOS SITIOS SAGRADOS, 2014).

En el pasado la cartografía era plenamente un elemento de conocimiento y control estatal, en cuya elaboración no cabe duda que agentes locales como los indígenas participaron como guías o bogas, hoy sectores diversos de la sociedad civil en compañía de los indígenas realizan una apropiación y elaboración cartográfica que visibiliza la existencia de estos pueblos, su derecho a continuar ocupando sus territorios y que como el último trabajo hace un contrapeso a la lectura cartográfica institucional que avanza lentamente o enfatiza elementos biogeográficos pero que desconoce elementos culturales o que no atiende plenamente las preocupaciones ambientales contemporáneas y al derecho a la vida de los pueblos en sus territorios.

\section{REFERENCIAS}

ACEVEDO LATORRE, Eduardo. Atlas de mapas antiguos de Colombia: siglos XVI a XIX. $4^{a}$ ed. Bogotá: Litografía Arco, 1997. 
ADONIAS, Isa. La cartografia da região amazônica: catálogo descritivo (1500-1961), Rio de Janeiro: Conselho Nacional de Pesquisas, Instituto Nacional de Pesquisas da Amazonia, 1963.

AMORIM, Antonio Brandao de. Amazonia Leyendas Ñangatú. Buenos Aires: Editorial Nova, 1943.

ANDRELLO, Geraldo. Cidade do índio. Transformações e cotidiano em Iauaretê. São Paulo: Instituto Sociambiental, Editora UNESP, Núcleo de Transformações Indígenas, 2006.

APPELBAUM, Nancy P. Dibujar la nación. La Comisión Corográfica en la Colombia del siglo XIX. Bogotá: Universidad de los Andes. Fondo de Cultura Económica, 2017.

ARANGO MONTOYA, Francisco. Colombia. Atlas indigenista. Bogotá: Litografía Arco, 1977.

ARCHIVO GENERAL DE LA NACIÓN. Catálogo Mapoteca. Sección de Mapas y Planos, Bogotá: Archivo General de la Nación, 2005.

ARHEM, Kaj. "Los Makuna en la historia cultural del Amazonas",Boletín Museo del Oro. Bogotá: Banco de la República, no. 30, 1991, p. 83-95.

BACHILLER CABRIA, Juan Vicente. Cartografía manuscrita de Brasil en las colecciones españolas (1500-1822). Salamanca: Universidad de Salamanca, 2008.

BANCO DE LA REPÚBLICA. Cartografía histórica del Atlántico. Exposición de cartografía regional. Barranquilla: Banco de la República, 2000.

BANCO DE LA REPÚBLICA. Cartografía histórica del Alto Magdalena. Honda, Girardot y Neiva. Bogotá: Banco de la República, 1999.

BANCO DE LA REPÚBLICA. Cartografía del Tolima Grande. Antigua Provincia de Mariquita y Neiva. Estado soberano del Tolima. Actuales departamentos del Tolima y Huila. Ibagué: Banco de La República, 1999.

BLANCO BARROS, José Agustín. Cartografía y geografía en el Boletín. Boletín de Historia y Antigüedades, n. 818, 2002, p. 647-652.

BLANCO BARROS, José Agustín. Atlas de mapas antiguos de Colombia. Bogotá: Archivo General de la Nación, Grupo Editorial Norma, 1992.

BEERMAN, Eric. Francisco Requena: la expedición de límites Amazonia, 1779-1795. Madrid: Compañía Literaria, 1996.

BITTENCOURT, Agnello. Dicionário amazonense de biografías: vultos do pasado. Rio de Janeiro: Conquista, 1973.

BRIAN Moser y DONALD Tayler. Tribes of the Piraparaná. The Geographical Journal. Vol. 129, 1963, p. 437-449. 
CABALZAR, Aloísio. "Petróglifos do Alto Rio Negro: visão contemporânea dos povos indígenas". In: Petróglifos sul-americanos: Theodor Koch-Grünberg. Organización Edithe Pereira. Belém: Museus Pareaense Emílio Goeldi; São Paulo: ISA, 2010. p. 11-16.

CABEZAS GELABERT, Lino. Cartografía, mapas y planos. In: CABEZAS, L.; LOPÉZ, I. (coords.). Dibujo y territorio: cartografía, topografía, convenciones gráficas e imagen digital. Madrid: Ediciones Cátedra, jul. 2015.

CABRERA, Gabriel. Los trabajos de la Compañía de María y el misionero Pedro Kok en el Vaupés colombiano, 1914-1949. Revista Colombiana de Ciencias Sociales: revista virtuale de la Universidad Católica Luisamingo, Medellín, n.2, 2019. Disponible:

https://www.funlam.edu.co/revistas/index.php/RCCS/article/view/2778/pdf. Acceso en: 08 feb. 2020.

CABRERA, Gabriel. Un siglo de fotografías del Alto río Negro, Vaupés, 1865-1965. Boletín de Antropología: revista virtuale de lo Departamento de Antropología de la Universidad de Antioquia, Medellín, n. 55, 2018. Disponible:

https://revistas.udea.edu.co/index.php/boletin/article/view/331150/20787362. Acceso en: 08 feb. 2020.

CABRERA, Gabriel. La fotografía de misiones y los indígenas del Alto Río Negro-Vaupés de Colombia y Brasil (1914-1965). História Unisinos: revista virtuale de Programa de Posgraduación en Historia de Unisinos, RS, n. 1, ene-abri. 2018b. Disponible en: http://revistas.unisinos.br/index.php/historia/article/view/htu.2018.221.03/60746129. Acceso en: 15 feb. 2020.

CABRERA, Gabriel. Los viajes de J. G. Ebehard por la Amazonia colombina. Historia y Sociedad: revista virtuale da Faculdad de Ciencias Humanas y Economicas de la Universidad Nacional de Colombia, Medellín, n. 31, jul-dic. 2016. Disponible en: https://revistas.unal.edu.co/index.php/hisysoc/article/view/55304/56602. Acceso en: 15 feb. 2020.

CABRERA, Gabriel. Los poderes en la frontera. Misiones católicas y protestantes, y Estados en el Vaupés colombo-brasileño, 1923-1989. Medellín: Universidad Nacional de Colombia, 2015a.

CABRERA, Gabriel. La representación del indio Uaupé. Una lectura sobre su iconografía, Boletín de Antropología: revista virtuale de lo Departamento de Antropología de la Universidad de Antioquia, Medellín, n. 50, jul-dic. 2015b. Disponible en:

https://revistas.udea.edu.co/index.php/boletin/article/view/25252/20863. Acceso en: 15 feb. 2020.

CABRERA. Gabriel. La Iglesia en la frontera: misiones católicas en el Vaupés 1850-1950. Bogotá: Universidad Nacional de Colombia, 2002.

CABAlZaR, A.; R., C. A., (eds.) Povos indígenas do Rio Negro: uma introdução à diversidade socioambiental do noroeste da Amazônia brasileira. $3^{\mathrm{a}}$ ed. São Paulo: Instituto Socioambiental, Federação das Organizações Indígenas do Rio Negro, 2006. 
COSTA, Cecilia da. Mapoteca. Relatório das atividades. Revista do Instituto Histórico e Geográfico Brasileiro, Rio de Janeiro, n. 461, jul.-set., 2013.

CORREA, François. Amazonia amerindia. Territorio de diversidad cultural, Bogotá: Instituto Colombiano de Antropología e Historia, Vol. 3, tomo 6, 2000.

CORREA, François. Por el camino de la Anaconda Remedio. Bogotá: Universidad Nacional de Colombia. Colciencias, 1996.

COUDREAU, Henri A. La France Equinoxiale Etude et voyage a traver les Guyanes et L’Amazonie, Atlas. Paris: Challamel Ainé Editeur, 1887.

DAMOISEAUX, Huberto. La misión del Vaupés diez años en la frontera brasilera 1914 a 1924. In: Las Misiones de la Compañía de María en los Llanos de San Martín. Villavicencio: Imprenta San José, 1923, p. LXIX-XCIX.

DELGADO ROZO, Juan David et al. 2013. Impactos territoriales en la transformación de la colonia a la república en la Nueva Granada. Bogotá: Universidad Nacional de Colombia.

DÍAZ GALINDO, Félix M. 1935. Monografía de la Comisaría del Vaupés (inédito).

DÍAZ ÁNGEL, Sebastián; MUÑOZ ARBELÁEZ, Santiago y NIETO OLARTE, Mauricio. Ensamblando la nación. Cartografía y política en la historia de Colombia. Bogotá: Ediciones Uniandes, 2010.

DOMINGO, Mariano. Pinzón y las raíces hispánicas de Brasil. Revista do Instituto Histórico e Geográfico Brasileiro. Rio de Janeiro, n. 462, p. 103-160, jan/mar., 2014.

DOMÍNGUEZ, Camilo A., GÓMEZ, Augusto J. y BARONA, Guido. Geografía física y política de la Confederación Granadina. Estado del Cauca. Territorio del Caquetá. Obra dirigida por el General Agustín Codazzi. Bogotá: COAMA, Fondo FEN, IGAC, 1996.

DOMÍNGUEZ, Camilo A. Amazonia colombiana. Visión general. Bogotá: Banco Popular, 1985.

DUTRA, Israel Fontes. "A história da origem espiritual dos povos indígenas do Uaupés", Tellus, Campo Grande, n. 21, p. 235-253, 2011.

EPPS, Patience. A Grammar of Hup. New York: Mouton Grammar Library, Vol. 43, 2008.

FARIA, Maria Dulce de. Catálogo da Coleção Cartográfica e Iconográfica Manuscrita do Arquivo Histórico Ultramarino. Rio de Janeiro: Museu de Astronomia e Ciências Afins, 2011.

FERNÁNDEZ-SALVADOR, Carmen. Encuentros y desencuentros con la frontera imperial. La iglesia de la Compañía de Jesús de Quito y la misión en el Amazonas (siglo XVIII). Madrid: Iberoamericana-Vervuert, 2018. 
FERNÁNDEZ-SALVADOR, Carmen. De la descripción al mapa: relatos de viajes y cartografía del Amazonas en el siglo XVII. In: MOSCOSO, S. G. (comp.). Enigmas: geografía, expediciones y cartografía de las Américas. Quito: Universidad San Francisco de Asís, 2013, p. 72-86.

GENTIL, Gabriel dos Santos. Povo Tukano - cultura, história e valores. Manaus: Editora da Universidade Federal do Amazonas, 2005.

GOLDMAN, Irving. Los cubeo. Indios del noroeste del Amazonas. México: Instituto Indigenista Interamericano, Ediciones especiales no. 49, 1968.

GUEDES, Max Justo. A construcão da imagem do país. A cartografia: a constituicão do país como território. In: PEREIRA, P. R. (Org.). 500 anos de Brasil na Biblioteca Nacional. Rio de Janeiro: Fundação Biblioteca Nacional, 2000, p. 96-101.

HARLEY, John Brian. La nueva naturaleza de los mapas. Ensayos sobre historia de la cartografía. México: FCE, 2005.

INSTITUTO GEOGRÁFICO AGUSTÍN CODAZZI. Paisajes fisiográficos de OrinoquiaAmazonia (ORAM) Colombia. Bogotá: Instituto Geográfico Agustín Codazzi, 1999.

JACKSON, Jean E. Identidad lingüística de los indios colombianos del Vaupés. Lenguaje y sociedad. Cali, p. 379-397, 1983.

KOCH.GRÜNBERG, Theodor. Petróglifos Sul-americanos. Belém: Museu Paraense Emílio Goeldi. Instituto Sociambiental, 2010.

KOCH-GRÜNBERG, Theodor. Dos años entre los indios. Bogotá: Universidad Nacional, 1995.

KOK, Pedro. Quelques notices ethonographiques sur les indiens du Rio Papuri. Anthropos, n. 20, p. 624-637, 1925.

MANSO PORTO, Carmen. Cartografia histórica portuguesa. In: Catálogo de manuscritos (siglos XVII-XVIII). Madrid: Real Academia de la Historia, 1999.

MARTINS, Valteir. Reconstrução fonológica do Protomaku oriental. 2005. Tese (Doctoral, Vrije Univesiteit). Amsterdam, Utrecht, LOT Dissertation Series, n. 104, 2005.

MEIRELlES FILHO, João. Grandes expedições a Amazônia brasileira. São Paulo: Metalivros, 2009.

MONTAÑEZ GÓMEZ, Gustavo. Elementos de historiografía de la geografía colombiana. In: BUITRAGO, F. L.; REY, G. (eds.). Discurso y razón. Una historia de las ciencias sociales en Colombia. Bogotá: Ediciones Uniandes, TM Editores, 2000, p. 53-82.

MOSER, Brian y TAYLER, Donald. Tribes of the Piraparaná. The Geographical Journal. vol. 129 , p. 437-458, 1963. 
NIETO OLARTE, Mauricio. Ensamblando la nación: cartografía y política en la historia de Colombia. Bogotá: Ediciones Uniandes, 2010.

NORONHA, José Monteiro de. Roteiro de viagem da cidade do pará, até as ultimas colonias do Sertao da Provincia. escrito en la villa de Barcellos por el Vicario General del Rio Negro el Padre José Monteiro de Noronha en el año de 1768. Typographia de santos \& Irmaos, 1862.

PORRO, Antonio. As crônicas do rio Amazonas. Notas etno-históricas sobre as antigas populações indígenas da Amazônia. Manaos: EDUA, 2016.

RABELO, Lucas Montalvão. A toponímia da região amazónica nos mapas do século XVI. In: MORGA, Antônio Emilio (org.). Encontro com a história e as suas deliciosas contradições. Manaus: EDUA, 2015, p. 155-168.

RAISG. Amazonia bajo presión. São Paulo: Instituto Sociambiental, 2012.

REIS, Arthur Cezar. Lobo d'Almada. Um estadista colonial. $3^{\text {a }}$ ed. Manaus: Academia Amazonense de Letras, Prefeitura Municipal de Manaus: Editora Valer, 2006.

RIBEIRO DE SAMPAIO, Francisco Xavier. 1825. Diario da viaje que em visita, e correiçao das povoaçoes da Capitania de S. Josze do Rio Negro fez o ouvidor, e Intendente Geral da misma Francisco Xavier Ribeiro de Sampaio no anno de 1774 e 1775. Lisboa: Typografia da Academia.

RICE, Hamilton. Further Explorations in the North-West Amazon Basin. The Geographical Journal, vol. 44, n. 2, p. 137-164, 1914.

RICE, Hamilton. The River Uaupés. The Geographical Journal, vol. 35, n. 6, p. 682-700, 1910.

RIVET, Paul; TASTEVIN, Constant. Affinites du Makú et du Puinâve. Journal de la Société des Américanistes de Paris, París, Nouvelle Serie, vol. 12, p. 69-82, 1920.

ROCQUE, Carlos. Grande enciclopédia da Amazônia, vol. 2. Belém do Pará: Amazônia Editora, 1967.

SAMPAIO, Patrícia Melo. Espelhos partidos: etnia, legislação e desigualdade na colônia. Manaus: Editora da Universidade Federal do Amazonas, 2012.

SANTOS, Claudio João Barreto dos y CASTIGLIONE, Luiz Henrique Guimarães. A atuação do IBGE na evolução da cartografia civil no Brasil. Terra Brasilis (Nova Série), 2014.

SANTOS, Francisco Jorge dos. Além da conquista: guerras e rebeliões indígenas na Amazônia pombalina. Manaus: Editora da Universidade do Amazonas, 1999.

SCOLFARO, Aline et al. Cartografia dos sítios sagrados: iniciativa binacional BrasilColômbia. Salvaguarda do Patrimônio Cultural Imaterial do Noroeste Amazônico. São Paulo, Instituto Socioambiental, 2013. 
SEVILLA, Ana; SEVILLA, Elisa. Amazonia: una tierra incógnita. In: MOSCOSO, S. G. (ed.). Enigmas: geografía, expediciones y cartografía de las Américas. Quito: Universidad San Francisco de Asís, 2013, p. 87-98.

SORENSEN, Arthur P. Multilingualism in the Northwest Amazon. American Anthropologist: publicación de la Asociación Americana de Antropología, n. 6, dic. 1967. Disponible en: https://anthrosource.onlinelibrary.wiley.com/doi/epdf/10.1525/aa.1967.69.6.02a00030. Acceso en: 15 feb. 2020.

SOUTO, Alanna. Os indígenas na cartografia da América lusitana. Boletim do Museu Paraense Emílio Goeldi. Cienc. Hum., Belém, n.3, sep.-dic. 2017. Disponible en: http://www.scielo.br/pdf/bgoeldi/v12n3/1981-8122-bgoeldi-12-3-0817.pdf. Acceso en: 15 feb. 2020.

SOUZA, Boanerges Lopes de. Do Rio Negro ao Orenoco. Río de Janeiro: Ministério da Agricultura, Conselho Nacional de Proteção aos Índios, 1959.

SOUZA, Boanerges Lopes de. Índios e explorações geográficas. Río de Janeiro: Ministerio de Agricultura. Conselho Nacional de Proteção aos Índios. Publicação no. 110, 1955.

SPRUCE, Richard. Notas de un botánico en el Amazonas y los Andes. Quito: Abya-Yala. Tierra Incógnita n. 21, 1996.

TORRES LANZAS, Pedro. Archivo General de Indias. Catálogo de Mapas y Planos de Panamá, Santa Fe y Quito. Madrid: Ministerio de Cultura, 1985.

TOVAR, Hermes. Los fantasmas de la memoria: poder e inhibición en la historia de América Latina, Bogotá: Universidad de los Andes, 2009a.

TOVAR, Hermes. Imágenes a la deriva. Los mapas o las habitaciones del pasado y la nostalgia, Bogotá: Archivo General de la Nación, 2009b.

VARGAS, Héctor y GARCÍA, João Carlos. A história da cartografia nos países ibeoamericanos. Terra Brasilis (Nova Série), n. 7-9, p.1-13, 2007.

VERGARA Y VELASCO, Francisco Javier. Nueva Geografía de Colombia. Tomo I. Bogotá: Imprenta de Vapor, 1901.

WALLACE, Alfred Russell. Una narración de viaje por el Amazonas y el Rio Negro. Iquitos: IIAPCETA, Monumenta amazónica, serie D, n. 2, 1992.

WRIGHT, Robin M. Lucha y supervivencia en el noroeste de la Amazonia. América indígena. México, Instituto Indigenista Interamericano, vol. 43, n. 3, p. 537-554, 1983.

WRIGHT, Robin M. History and Religion of the Baniwa Peoples of the Upper Rio Negro, University Microfilms International, 1981. 
ZÁRATE BOTÍA, Carlos Gilberto. Introducción. La Universidad Nacional y la demarcación de la frontera amazónica. In: BOTÍA, C. G. Z. (comp.). Memoria histórica sobre los límites entre la República de Colombia i el Imperio del Brasil. Bogotá: Universidad Nacional de Colombia, 2018, p. 15-23.

SZENTMARTONYI, Ignacio. 1749-55. Sequente Notiatiate de Rio Negro. Wright, Robin Michael. Indian slavery in the Northwest Amazon. Boletin do Museu Paraense Emilio Goeldi. Serie antropología. vol. 7. n. 2, p. 149-179, 1991. 